\title{
LA ARQUEOMETRÍA DE MATERIALES CERÁMICOS: UNA EVALUACIÓN DE LA EXPERIENCIA ANDALUZA
}

\author{
ARCHAEOMETRY OF CERAMIC MATERIALS: AN EVALUATION OF THE ANDALUSIAN \\ EXPERIENCE
}

TOMÁS CORDERO RUIZ $(*)$

LEONARDO GARCÍA SANJUÁN $(* *)$

VÍCTOR HURTADO PÉREZ $(* *)$

JOSÉ MARÍA MARTÍN RAMÍREZ (***)

ÁNGEL POLVORINOS DEL RÍO (****)

RUTH TAYLOR $(* *)$

\section{RESUMEN}

Este artículo intenta valorar el impacto que la introducción de métodos de caracterización de materiales procedentes de la física y la química (y agrupados habitualmente bajo la denominación genérica de Arqueometría) ha tenido en la configuración metodológica de la investigación arqueológica de nuestro país durante las últimas dos décadas. Para ello se realiza un análisis bibliométrico de un ámbito específico de la aplicación de las técnicas arqueométricas, cual es el de la caracterización de materiales cerámicos dentro de la Arqueología andaluza. Las variables tenidas en cuenta incluyen aspectos tales como la cantidad de sitios arqueológicos muestreados y de muestras analizadas, su procedencia geográfica, los contextos cronológicos y funcionales de los que las muestras fueron tomadas y las técnicas analíticas empleadas.

\section{ABSTRACT}

This paper assesses the impact that the introduction of scientific methods for materials characterisation (conventionally grouped under the label of Archaeometry) has had

(*) Instituto de Arqueología de Mérida (CSIC. Junta de Extremadura-Consorcio de Mérida). Pza. España, 15. 06800 Mérida.

(**) Dpto. de Prehistoria y Arqueología. Universidad de Sevilla.

(***) Empresa de Gestión Medioambiental (EGMASA). Junta de Andalucía.

(****) Dpto. de Cristalografía, Mineralogía y Química Agrícola. Universidad de Sevilla.

Recibido: 13-IV-05; aceptado: 22-VIII-05. in the methodological configuration of Spanish archaeology over the last two decades. This is achieved through a bibliometric study of publications dealing with characterisation of archaeological ceramics from Andalucía (southern Spain). The variables handled in this study include aspects such as the number of sampled sites and items, their geographical provenance, the chronological and functional dimensions of the archaeological contexts they were taken from as well as the analytical techniques employed in their study.

Palabras clave: Arqueometría. Ciencia de Materiales. Cerámica. Bibliometría. Prehistoria. Historia Antigua.

Key words: Archaeometry. Materials science. Ceramics. Bibliometry. Prehistory. Ancient History.

\section{INTRODUCCIÓN}

En los últimos 25 años, la aplicación de técnicas científicas a la caracterización de materiales ha llegado a convertirse en un elemento fundamental en la investigación arqueológica. El análisis de la cerámica, en particular, se ha beneficiado del desarrollo o aplicación de técnicas químicas, físicas y mineralógicas que han sobrepasado ampliamente los límites de la información que se obtenía tradicionalmente de los artefactos cerámicos mediante su descripción macroscópico-morfológica (la conocida tipología), proporcionando así una nueva reserva 
de datos de los que obtener una valiosa comprensión de las sociedades del Pasado. Una nutrida literatura, tanto de carácter genéricamente arqueométrico (Anderson 1988; Bowman 1991; Orna 1996; Pollard y Heron 1996; Jakes 2004; Henderson 2000; Andrews y Doonan 2003; etc.), como específica del estudio de materiales cerámicos (Middleton y Freestone 1991; Sinopoli 1991; Lindahl y Stilborg 1995; Tite 1999; Barclay 2001; Whitbread 2001; Kilikoglou et al. 2002), ha dado cuenta del enorme avance que en poco tiempo ha experimentado este campo a nivel internacional, contribuyendo al planteamiento de problemas y temas de investigación arqueológica previamente considerados muy difíciles de tratar (correlación entre clasificaciones morfológicas y tecnológicas, grupos y tradiciones tecnológicas, procesos de elaboración y manipulación) o simplemente intratables (intercambio, procedencia y aprovisionamiento de materias primas, residuos y contenidos, diagnóstico funcional, etc.).

Dentro de la Arqueología española, la aplicación de métodos arqueométricos ha experimentado un notable avance en apenas quince años, como lo demuestra la realización de varias reuniones nacionales e internacionales (Vendrell-Saz et al. 1995; Capel Martínez 1999; Pérez Arantegui et al. 1999; Gómez Tubío et al. 2001; Roldán 2002; Feliú Ortega et al. 2004), los varios volúmenes generales publicados en los últimos años (Barrio Martín 1990; Vila i Mitjà 1991; De la Bandera Romero y Chaves Tristán 1994; Cañabate Guerrero 1998) y los numerosos informes, memorias y libros monográficos que vienen apareciendo como resultado de proyectos de investigación específicos. En el caso de la Arqueometría de materiales cerámicos (vestigios, recordemos, particularmente visibles y presentes en el registro arqueológico), la producción científica ha crecido de forma vigorosa, con la paulatina incorporación y fijación de lo que podríamos considerar un marco metodológico de estudio estandarizado (Capel Martínez y Delgado 1978; Peláez Colilla 1983; Capel Martínez et al. 1990- 1995; García Heras y Olaetxea 1992; González Vilches 1994; Cañabate Guerrero y Sánchez Vizcaíno 1995; García Heras 1995; Pérez Arantegui et al. 1996; Aguilera Martín 1998; Bernal Casasola y García Jiménez 1999; Buxeda i Garrigós 1999; Polvorinos del Río 2001a; 2001b) y con su aplicación a una extensa gama de situaciones empíricas de las que más adelante se examinan algunos ejemplos.
Ahora bien ¿cómo valorar este progreso dentro del contexto general de la investigación europea? Hace apenas unos años, un estudio bibliométrico de la producción científica relativa a estudios arqueométricos de materiales cerámicos concluía que la introducción y desarrollo de la Arqueometría en España era insuficiente y lenta comparada con otros países de nuestro entorno (García Heras 1997:129). La evaluación de los primeros años de aplicación de las técnicas arqueométricas en nuestro país sugería la existencia de una serie de problemas, entre los cuales destacaba la escasa y pobre coordinación entre la interpretación arqueológica y el análisis arqueométrico, planteándose así una serie de cuestiones relativas al futuro desarrollo de esta disciplina (García Heras y Olaetxea 1992; García Heras 1997; 2003), lo cual era básicamente coincidente con valoraciones anteriores (pero igualmente escépticas) acerca de la capacidad de la Arqueología española para renovarse mediante la incoporación de métodos científicos procedentes de múltiples disciplinas (Vila i Mitjà y Estévez Escalera 1989: 272).

Contando con algunos años más de perspectiva (años en los que, indiscutiblemente se ha producido un crecimiento cuantitativo notable de este campo) y atendiendo al impacto que la Arqueometría está teniendo en la disciplina arqueológica (un impacto que resulta difícil no calificar de revolucionario), parece legítimo interrogarse acerca de la naturaleza de la relación actual entre Arqueología, Ciencias Arqueológicas y Ciencias Exactas, examinando los resultados que el proceso más o menos espontáneo de integración de complejos procedimientos y técnicas científicas de análisis procedentes de la física y de la química está teniendo en una disciplina que de por sí (y especialmente en el caso de España) tiene históricamente un importante componente de arraigo en las humanidades y la artes.

En otras palabras, ¿está el desarrollo de la Arqueometría adquiriendo todo su potencial epistemológico como motor de renovación de la ciencia/ disciplina arqueológica? ¿Son, en la práctica, las técnicas científicas de análisis empleadas como una parte integral de la interpretación arqueológica del Pasado, o se está convirtiendo la arqueometría en un subcampo de la Arqueología, con sus propias agendas, discursos y objetivos, un tanto al margen de la interpretación sustantiva de las sociedades humanas? ¿Qué efectos está teniendo, en su caso, esta renovación en la percepción que los/as practicantes de la Arqueología tienen de la naturaleza y ob- 
jetivos de su práctica científica? ¿Está sirviendo la extensión de los procedimientos y técnicas de análisis arqueométrico al desarrollo (o, digamos, enriquecimiento) de agendas teóricas y epistemológicas bien meditadas e interesadas en la resolución de cuestiones de carácter social, tecnológico o económico? ¿Incluyen el diseño de los proyectos arqueológicos en nuestro país la formulación de preguntas innovadoras y adecuadas cuya respuesta exija inherentemente el empleo de la arqueometría? ¿O se impone una realidad distinta donde el empleo de las técnicas científicas depende de otros factores mucho más coyunturales como la disponibilidad o proximidad de especialistas y recursos materiales, técnicos y financieros?

Nuestro interés o preocupación por estas cuestiones, que posiblemente sea compartido por la creciente comunidad de arqueólogos/as y científicos/ as españoles/as implicados/as en el estudio del Pasado a través de la Arqueometría, deriva del trabajo que venimos desarrollando en la Universidad de Sevilla, en colaboración con otras instituciones, desde hace en torno a una década, esencialmente en los campos de la Arqueometría de materiales metálicos y cerámicos de la Prehistoria peninsular (en relación con los últimos, ver por ejemplo Gómez Morón y Polvorinos del Río 1997; Polvorinos del Río 1998-1999; Polvorinos del Río et al. 19992001-2005; Gómez Morón et al. 1995-1999; Estrada et al. 1999). Planteadas tales preguntas (en un sentido reflexivo y autocrítico), el procedimiento más obvio para intentar obtener las correspondientes respuestas es, posiblemente, el análisis bibliométrico. El objetivo de este estudio es, por tanto, revisar y aquilatar la naturaleza de la investigación en Arqueometría cerámica que se está llevando a cabo en nuestra comunidad autónoma mediante la selección de una muestra bibliométrica amplia que pueda resultar representativa de la investigación realizada en los últimos 25 años (1).

Dado que ya existe el precedente de un trabajo que ha abordado la cuestión a nivel nacional (Gar-

(1) Este trabajo resulta del Proyecto "Desarrollo e Incorporación en Internet de una Base de Datos Arqueométricos de Andalucía" llevado a cabo, entre los años 2002 y 2003 y financiado por la Consejería de Educación y Ciencia de la Junta de Andalucía dentro del PAI (Plan Andaluz de Investigación) como colaboración entre los grupos de investigación ATLAS. Territorios y Paisajes en la Prehistoria Reciente de Andalucía (Código HUM694), del Departamento de Prehistoria y Arqueología de la Universidad de Sevilla (www.us.es/atlas) y Teledetección y Geoquímica (Código RNM-185), del Departamento de Cristalografía, Mineralogía y Química Agrícola. Esta base de datos puede ser consultada en http://www.aloj.us.es/rnm185/ cía Heras 1997) y que el volumen de información es ya bastante amplio y diverso, se han establecido una serie de criterios de delimitación del ámbito y propósito del estudio de datos con el objeto de hacerlo manejable y darle sentido. Por una parte, hemos circunscrito el estudio a la producción bibliométrica relativa a la Arqueología andaluza (en cualquier periodo histórico), que es el contexto en el que, de forma no exclusiva pero sí preferente, se ha desarrollado nuestro trabajo. No creemos que ello, sin embargo, suponga necesariamente una limitación para los resultados del estudio, puesto que la diversidad de organismos, individuos, grupos y proyectos implicados (en ningún caso andaluces de forma exclusiva), así como la propia diversidad cronológica y funcional del registro arqueológico andaluz garantiza una suficiente generalidad y amplitud en los resultados, así como una razonable representatividad del estado de la cuestión a nivel nacional. El hecho de que tres de las cinco reuniones nacionales de Arqueometría hasta ahora celebradas en España hayan sido organizadas por universidades andaluzas (Granada en 1995, Sevilla en 1999 y Cádiz en 2003) sugiere el interés que este campo ha suscitado en los grupos y equipos de investigación de nuestra comunidad autónoma.

Por otra parte, el periodo de producción bibliográfica considerado en este artículo se circunscribe a los años comprendidos entre 1979 y 2002, lo cual se explica en parte por que la compilación bibliográfica original se realizó en 2003 y en parte por que la bibliografía publicada en los dos años más recientes no está siempre disponible con facilidad dado el desfase de varios meses con que, frecuentemente, llegan los trabajos a las bibliotecas (en todo caso, el rápido ritmo de producción bibliográfica hace que un estudio bibliométrico de esta naturaleza tienda de cualquier manera a quedar obsoleto con respecto a la situación presente en el plazo de apenas una década). Por otra parte, se ha restringido la compilación bibliográfica a los trabajos relativos a caracterización de materiales, no incluyéndose otros estudios que, aún siendo de gran importancia, constituyen una fracción cuantitativamente más restringida de toda la producción bibliográfica de la arqueometría de materiales cerámicos, cual es el caso de la datación por Termoluminiscencia (por ejemplo Calderón et al. 1989; Benéitez et al. 1998-2004) o identificación de residuos orgánicos (Cañabate Guerrero y Sánchez Vizcaíno 1995; 1999; Bernal Casasola y Petit Domínguez 1999). Las publicaciones estudiadas proceden de fuentes 


\begin{tabular}{|l|c|c|c|c}
\hline & PERIODO & $\begin{array}{c}\text { TÍTULOS } \\
\text { INDIVIDUALES }\end{array}$ & $\begin{array}{c}\text { MUESTRAS } \\
\text { CERÁMICAS }\end{array}$ & YACIMIENTOS \\
\hline 1. Muestra general & $1979-2002$ & 59 & 1382 & 80 (aprox.) \\
\hline 2. Muestra específica & $1979-2002$ & 38 & 976 & 60 \\
\hline 3. Estudio García Heras 1997 & $1972-1995$ & 223 & 6716 & \\
\hline
\end{tabular}

Tab. 1. Resumen cuantitativo de las muestras bibliográficas en estudio.

bastantes dispersas, incluyendo informes y monografías de yacimientos, revistas de Arqueología, revistas especializadas y actas de las conferencias.

En conjunto, una vez tenidos en cuenta los criterios de delimitación del ámbito empírico a estudiar, se ha contabilizado una muestra total de 59 publicaciones aparecidas entre 1979 y 2002. Como quiera que, por razones de accesibilidad, solo los materiales de una de las tesis doctorales han sido incluidos en el estudio, ello supone un total de 1382 muestras cerámicas de aproximadamente 80 yacimientos arqueológicos, correspondientes exclusivamente a estudios que tratan de la presentación de resultados analíticos arqueométricos de materiales cerámicos de Andalucía. De esa muestra general se ha realizado una valoración más detallada de una muestra específica de 38 trabajos que representan un total de 976 muestras cerámicas procedentes de 60 yacimientos arqueológicos distintos. El subconjunto utilizado para el estudio detallado representa aproximadamente el $64 \%$ de los títulos individuales, el $71 \%$ de las muestras y el $75 \%$ del número total de yacimientos incluidos en la muestra general.

El análisis bibliométrico y las valoraciones se han llevado a cabo, por tanto, en dos planos distintos: el primero pretende dar una perspectiva general del tema, basándose fundamentalmente en el año de publicación y en el número de muestras incluidas en los estudios, mientras que el segundo, basado en un número más pequeño de títulos individuales (la muestra más pequeña), explora sus contenidos con mayor profundidad, incluyendo la cronología de los materiales bajo estudio, el tipo de yacimiento arqueológico en que se han encontrado y las técnicas científicas a las que se habían sometido. Los detalles cuantitativos de ambos, la muestra preliminar y el grupo subsiguiente, se muestran en la tabla 1.

En comparación, el estudio bibliométrico de las publicaciones arqueométricas de cerámicas llevado a cabo por García Heras (1997) a escala nacional listaba un total de 223 títulos individuales y 6716 muestras publicadas entre 1972 y 1995 . Aunque estas cifras no son directamente comparables con las del presente estudio (diferentes periodos de tiempo y diferente ámbito geográfico), proporcionan una idea aproximada de la importancia relativa del volumen de estudios arqueométricos sobre las cerámicas procedentes del registro arqueológico andaluz. De hecho, el volumen de publicaciones y de muestras estudiados en el presente trabajo sería equivalente a un porcentaje aproximado del $20 \%$ de muestras y el $26 \%$ de publicaciones de la producción nacional de Arqueometría cerámica (Andalucía comprende aproximadamente el 17,2\% del territorio nacional y el $18 \%$ de su población). En el trabajo aquí presentado, por otra parte, se examinan algunos parámetros que no fueron incluidos en el estudio de García Heras, como se describe a continuación.

\section{PERSPECTIVA GENERAL}

Partiendo de los datos de la muestra general, el año de publicación de los títulos incluidos en esta muestra nos permite ver las tendencias evolutivas del volumen de estudios arqueométricos publicados en los últimos 25 años, mientras que el número de muestras por estudio se puede tomar como una indicación general de la naturaleza cuantitativa de las colecciones estudiadas.

\subsection{Evolución y carácter de la literatura científica}

Mientras que el primer estudio arqueométrico español fue publicado en 1972 (García Heras y Olaetxea 1992: 266), el primer estudio publicado sobre materiales cerámicos andaluces es, al menos hasta donde conocemos, el artículo de J. Capel Martínez, J. Linares González y F. Huertas García (1979). La figura 1 muestra el número de publicaciones correspondiente a cada uno de los cuatro periodos de cinco años entre 1980 y 2000, mientras que la figura 2 desglosa el número de estudios pu- 


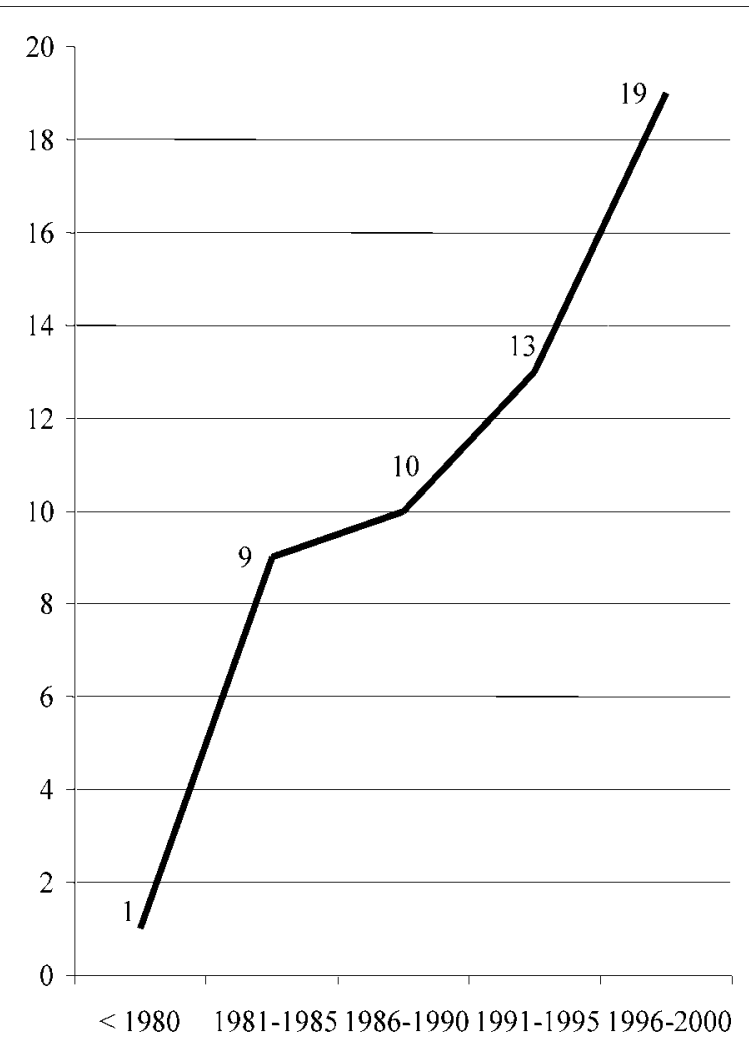

Fig. 1. Evolución del número de publicaciones por periodo de cinco años entre 1980 y 2000.

blicados en cada año. Los resultados de los dos resúmenes, tomados combinadamente, son una clara ilustración de la doble tendencia que está siguiendo el desarrollo de los estudios de Arqueometría cerámica en Andalucía. El número de publicaciones por lustro ilustra el sustancial incremento de estudios arqueométricos conforme estas técnicas se hacen más y más habituales en la investigación arqueológica. No obstante, aunque los estudios arqueométricos son generalmente más numerosos, el uso de estas técnicas analíticas aún no se ha convertido en una constante de la investigación arqueológica, como ilustra su irregularidad de un año a otro año.

Esta aparente irregularidad puede ser mejor explicada por la existencia de publicaciones puntuales tales como las actas de conferencias o monografías que contienen un gran número de estudios arqueométricos. Así, por ejemplo, el gran número de publicaciones de 1985 corresponde a una serie de estudios de J. M. Rincón publicados en Cástu-

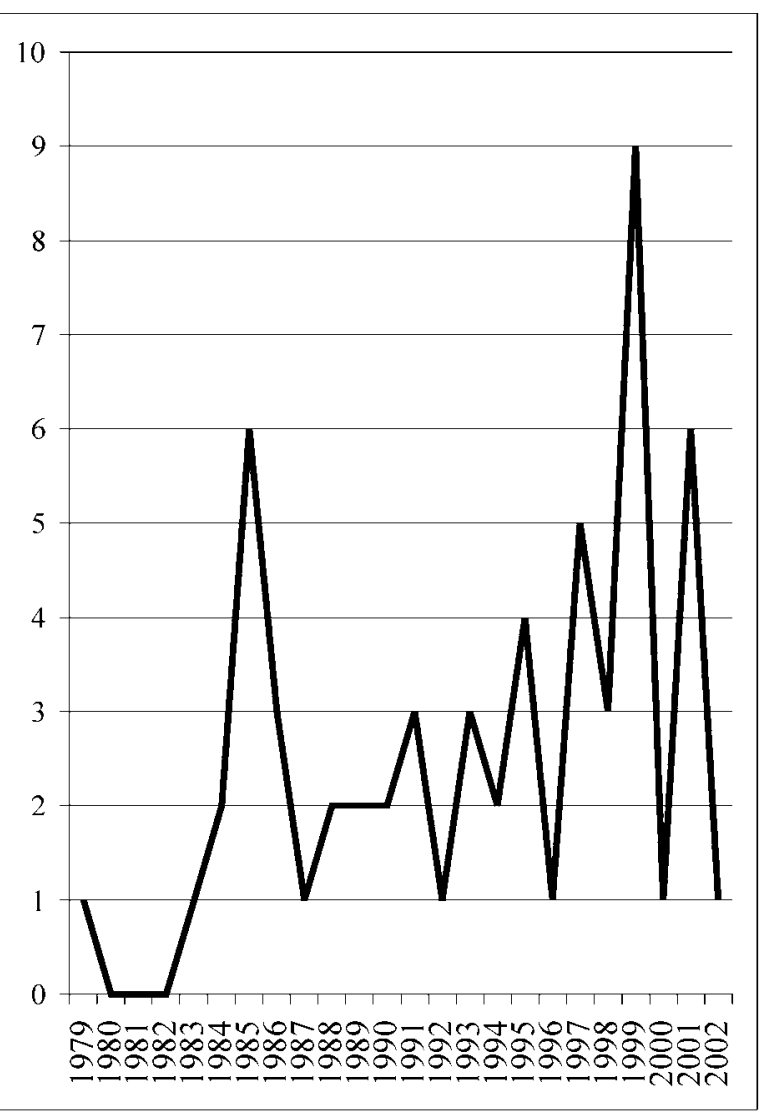

Fig. 2. Número de títulos individuales publicados por año.

lo V(Rincón 1981;Blázquez et al. 1985), mientras que el elevado número de trabajos aparecidos en 1999 refleja la publicación de las actas de los dos primeros congresos nacionales de Arqueometría celebrados en Granada en 1995 (Capel Martínez 1999) y Zaragoza en 1997 (Pérez Arantegui et al. 1999), mientras que el de 2001 corresponde a las actas del III Congreso Nacional de Arqueometría llevado a cabo en Sevilla en 1999 (Gómez Tubío et al. 2001). Estas publicaciones puntuales reflejan sin duda un interés genuino en la presentación de estudios arqueométricos, pero subraya la importancia de las publicaciones especializadas, lo que genera un cierto (y paradójico) confinamiento de estos estudios en medios de difusión muy específicos de su campo.

La distribución de los trabajos por clases de publicaciones es bastante regular. Los artículos aparecidos en revistas del campo de ciencia de materiales, fundamentalmente el Boletín de la Sociedad Española de Cerámica y Vidrio, suponen el bloque 


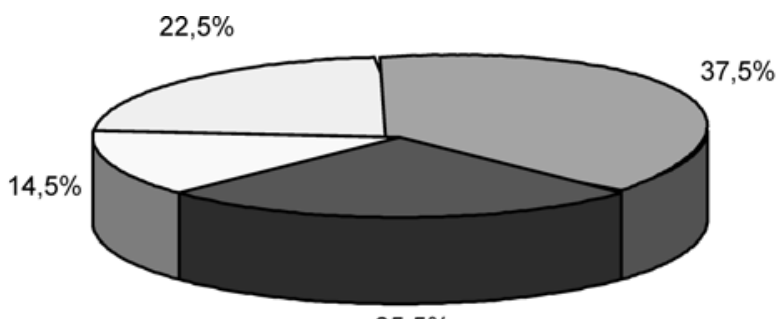

$25,5 \%$

$\square$ monografia o volumen editado $\square$ artículo en revista arqueológica $\square$ artículo en revista especializada $\square$ actas de congresos

Fig. 3. Tipo de publicación como porcentaje del número total de estudios.

más pequeño (14,5\%), mientras que los trabajos publicados en revistas arqueológicas alcanzan el $25,5 \%$. Las actas de congresos y conferencias constituyen asimismo un vehículo importante de publicación para los trabajos $(22,5 \%)$, especialmente las de los congresos nacionales de Arqueometría. Pero el bloque más significativo de los títulos $(37,5 \%)$ aparecen en monografías, básicamente informes relativos a un yacimiento único donde los estudios arqueométricos aparecen en capítulos separados, a menudo como "apéndices" técnicos. Este último grupo dejar traslucir una noción epistemológica del registro arqueológico donde la Arqueometría constituye una "ciencia auxiliar" separada de la "auténtica" Arqueología, más que una parte inherente de su cuerpo de procedimientos analíticos. El libro de Navarrete Enciso et al., Cerámicas Neolíticas de la Provincia de Granada (1991), constituye una categoría de publicación excepcional en la Arqueometría de materiales cerámicos de Andalucía (y en la arqueometría andaluza por extensión) en tanto que estudio en profundidad (mediante un muestreo amplio) de un tipo de materiales bien definidos cronológica y geográficamente.

Mención aparte merece el tema de las tesis doctorales, con independencia de que hayan sido publicadas o permanezcan inéditas. En el periodo de 23 años considerado aquí, han sido seis las tesis doctorales realizadas con la Arqueometría cerámica andaluza como tema, concretamente las de M. C. González Vílchez (1982), F. Contreras Cortés (1985), V. Galván Martínez (1991), M. J. Feliú Ortega (1993), M. A. Ontalba Salamanca (2000) y E. Fernández Navarro (2002). La tesis de la Dra. J. Capel Martínez (1981), que ha contribuido posteriormente con numerosos trabajos a la investigación de Arqueometría cerámica andaluza, no estudiaba materiales de esta región.
El número de tesis doctorales no es en sí mismo necesariamente muy bajo: resulta una media de casi una tesis doctoral por cada cuatro años, lo cual, tratándose de un campo de investigación relativamente novedoso, no es desdeñable. Se observa asimismo un equilibrio en la procedencia institucional de los/as investigadores/as: tres de las tesis han sido presentadas en departamentos de Prehistoria y Arqueología (Universidad de Granada y Universidad Autónoma de Madrid), mientras que las otras tres proceden de departamentos o centros de investigación en el campo de la física y la química (universidades de Cádiz y Sevilla). Visto desde el prisma de la investigación arqueológica, sin embargo, es difícil no concluir que tres tesis doctorales en 25 años en torno a un tema que ha experimentado en la Arqueología anglosajona una verdadera eclosión, es un tanto insatisfactorio. De hecho, resultan escasas las tesis doctorales realizadas a partir de la aplicación de métodos arqueométricos en general en todas las áreas de Prehistoria y Arqueología de las universidades andaluzas en los últimos 30 años. Por poner un ejemplo, en el Departamento de Prehistoria y Arqueología de la Universidad de Sevilla (la de mayor tamaño de Andalucía por número de alumnos/as y producción investigadora), tan solo una de las 41 tesis doctorales presentadas entre 1975 y 2004 (2) tiene un componente arqueométrico sustancial (en este caso arqueometalúrgico) en su metodología de investigación (M. Hunt Ortiz, Minería y Metalurgia Prehistórica en Andalucía Occidental, 1998), mientras que ni una sola del centenar de tesinas y trabajos de investigación doctorales presentados entre 1960 y 2003 ha sido de carácter estrictamente arqueométrico. Estos datos resultan desalentadores si se comprueba que numerosos de estos trabajos de investigación tienen como tema principal el análisis de conjuntos artefactuales, en cuyo diseño la Arqueometría parece no haber jugado papel alguno.

Estas cifras sugieren en primer lugar que, dentro de la Arqueología andaluza, la consolidación de la Arqueometría en general, y de la Arqueometría cerámica en particular, dista de ser satisfactoria, a pesar del constatado incremento en el número de publicaciones y tesis doctorales. En segundo lugar, realza la cuestión del limitado lugar que la Arqueometría ocupa en la formación de los arqueólogos, un tema sobre el que ya ha llamado la atención

(2) Existe un listado exhaustivo disponible en www.us.es/ dpreyarq/web 


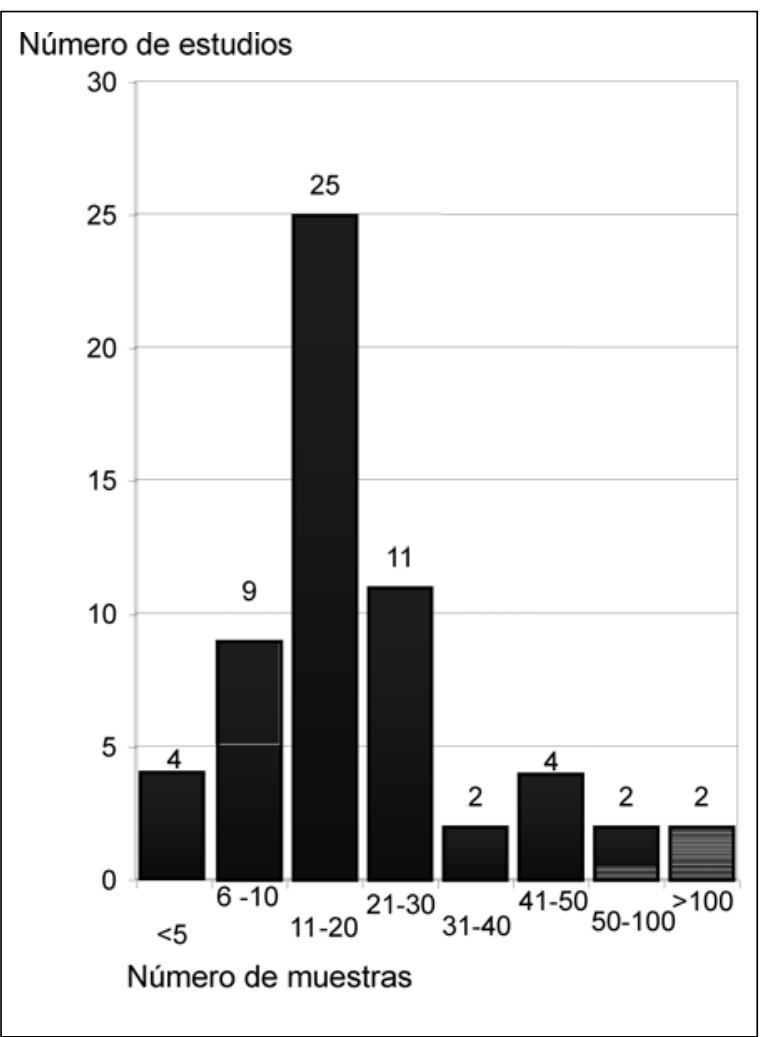

Fig. 4. Número de muestras por estudio.

García Heras (1997:134; 2003). De hecho, solo con mucha lentitud las técnicas arqueométricas se están integrando en la formación universitaria de los/as arqueólogos/as en Andalucía y en España. Aunque quizás sea poco razonable pretender que la formación especializada se imparta de forma extensiva, todos/as los/as arqueólogos/as deberían ser conscientes del potencial de la aplicación de técnicas científicas a los materiales arqueológicos, y estar informados de la existencia de centros de investigación o laboratorios especializados en este tipo de análisis (Barclay 2001).

\subsection{Tamaño de las series de muestras analizadas}

A partir del tamaño de las colecciones de muestras por estudio es posible observar asimismo algunas tendencias bien marcadas. Es digno de señalarse que las publicaciones aquí estudiadas ofrecen una variedad sorprendentemente amplia en cuanto al número de muestras estudiadas, desde tan solo 2 hasta 133, aunque el número de estudios, por tama-

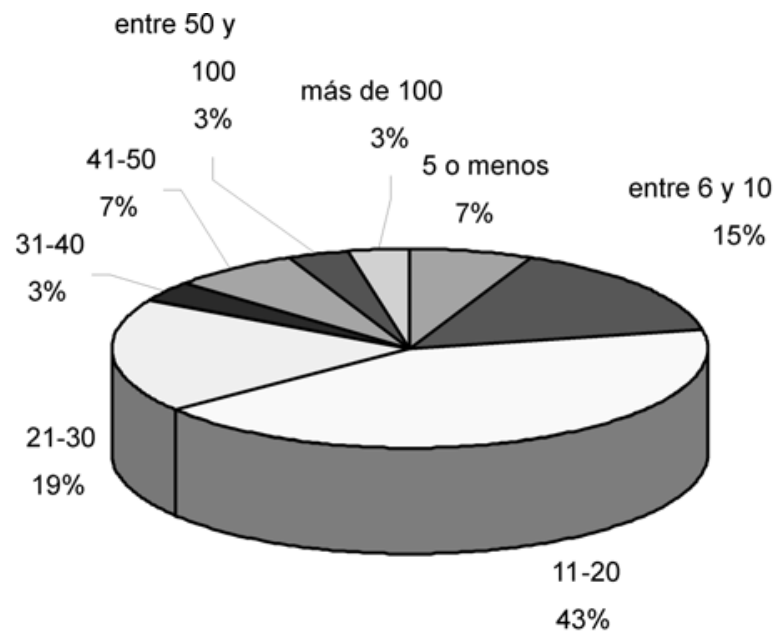

Fig. 5. Recuento del número de muestras por estudio (como porecentaje del número total de estudios).

ño de colección, está distribuido de modo irregular. El número medio de muestras por artículo publicado está en torno a 23, aunque en realidad en torno al 75\% de los estudios están basados en menos de 23 muestras, ya que unas pocas colecciones grandes suben la media desproporcionadamente a su frecuencia. Véase como, tanto en los valores brutos como en los porcentajes (Figs. 4 y 5), los tamaños más frecuentes de colecciones oscilan entre 11 y 20 muestras mientras que las colecciones grandes (más de 30 muestras) son escasas. En contraste, las colecciones pequeñas son relativamente frecuentes: el $22 \%$ de los estudios están basados en 10 o menos muestras, cifras idénticas a las observadas por García Heras a nivel nacional (1997: 133). Ello sugiere que los estudios arqueométricos tienden a enfocarse en un número muy selecto de muestras. Aunque pocos artículos son explícitos acerca de los criterios de selección de muestras, el reducido número medio de las mismas puede obedecer a muy diversas razones, entre las cuales seguramente no juegan un papel menor las limitaciones de recursos, tiempo y dinero.

La consecuencia más inmediata de la limitación cuantitativa de las colecciones de muestras es que los estudios arqueométricos de cerámicas de Andalucía raramente ofrecen resultados estadísticamente viables, ya que, para eso, se requeriría una colección de más de 30 muestras. Más aún, y parcialmente como consecuencia del pequeño tamaño de las colecciones consideradas, la comparación de los resultados, tanto en el plano de los yacimientos como más allá (territorios, áreas de captación e in- 
tercambio), se ve considerablemente dificultado. Esto ha creado a su vez una limitación a la integración de los resultados analíticos en la interpretación, ya que a menudo, la significación de los resultados más allá de la simple muestra manejada (por ejemplo a nivel social, ideológico o territorial) no se puede inferir.

Naturalmente, estudios como los llevados a cabo por V. Galván Martínez (1991) y Navarrete et al. (1991), así como las otras tesis doctorales antes citadas, son excepcionales en cuanto al número de muestras manejadas. Ambos presentan los resultados del análisis de una gran muestra de materiales (133 y 122 muestras cerámicas respectivamente) procedentes de varios yacimientos, haciendo especial hincapié en la significación regional de los resultados analíticos. Al contrario que los diferentes estudios arqueométricos examinados en la presente valoración, estos dos estudios fueron llevados a cabo dentro de un marco metodológico y de un diseño de investigación que daba desde el principio particular importancia a los materiales bajo estudio dentro de una perspectiva más amplia, regional y cronológica.

\section{ASPECTOS ESPECÍFICOS}

El subconjunto utilizado para el estudio detallado (estas referencias se identifican por un punto sangrado a la derecha en la lista bibliográfica del Apéndice, para distinguirlas de la muestra inicial) contiene un total de 38 publicaciones, 976 muestras y 60 yacimientos. Su análisis ha sido estructurado por dos temas principales que constituyen el nervio de la indagación bibliométrica llevada a cabo: el primero se interesa por la procedencia de los materiales muestreados, incluyendo la información regional y contextual (tipo de yacimiento y cronología), el segundo se orienta a los análisis de las muestras, a las técnicas aplicadas y a la evolución de dichas técnicas a lo largo del tiempo.

\subsection{Procedencia geográfica de las muestras}

El desglose del número de muestras y yacimientos estudiados por provincia, que se presenta en la tabla 2, muestra una distribución bastante irregular de los estudios arqueométricos en Andalucía. Las provincias de Sevilla, Granada y Almería acumulan el mayor volumen de muestras con más de 200 estudiadas en cada provincia. Huelva, Cádiz, Córdoba y Jaén presentan un volumen de muestras mucho menor comparado con la cabeza de la tabla y la distancia entre Almería y Huelva (con el cuarto volumen en número de muestras), es considerable. Málaga aparece como la provincia más pobre en estudios arqueométricos de materiales cerámicos, con solo 16 muestras de tan solo 2 yacimientos arqueológicos. Como era de esperar, el volumen de muestras y el número de yacimientos reflejan la misma tendencia en su distribución.

Estas marcadas diferencias deben ser consideradas producto de la interacción de varios factores, entre los que la presencia del respaldo de la investigación académica y de una infraestructura de laboratorios parece ser de importancia clave. De hecho, cuando se consideran las causas subyacentes tras el desigual interés suscitado por los materiales arqueológicos en cada provincia, merece la pena intentar establecer si es la naturaleza del material arqueológico o la estrategia de investigación lo que ha condicionado la aplicación de las técnicas arqueométricas, o si lo que ha dado más ímpetu a estos estudios en unos lugares que en otros es la existencia de una infraestructura institucional de investigación y un equipo de especialistas (por ejemplo en un centro universitario de primer orden, lo que en Andalucía, hasta los años 1990, ha querido decir básicamente Granada o Sevilla). Es significativo que tanto Granada como Almería se beneficien de los estudios de larga duración llevados a cabo a escala regional (Navarrete Enciso 1991 y Galván Martínez 1991, respectivamente), el primero como proyecto conjunto entre el Departamento de Prehistoria de la Universidad de Granada y los laboratorios del CSIC situados en Zaidín (García Heras y Olaetxea 1992: 267), el último como tesis doctoral de la Universidad Autónoma de Madrid.

\subsection{Número de yacimientos por estudio}

Aproximadamente el $77 \%$ de las publicaciones encuestadas tratan materiales de un solo yacimiento (Fig. 6), y solo una publicación (Navarrete Enciso et al. 1991) incluye datos de más de 10 yacimientos. En conjunto, por tanto, la naturaleza de los estudios se puede describir como territorialmente aislada o separada de un contexto comparativo e interpretativo espacial amplio, que vaya más allá del contexto particular de cada yacimiento arqueológico. Sea como resultado de la investigación específica de un 


\begin{tabular}{|c|c|c|}
\hline PROVINCIA & \begin{tabular}{|l|}
$\mathbf{N}^{\circ}$ YACIMIENTOS/ \\
$\mathbf{N}^{\circ}$ DE MUESTRAS \\
\end{tabular} & NOMBRES YACIMIENTOS \\
\hline Almería & $\begin{array}{l}9 \text { yacimientos, } \\
202 \text { muestras }\end{array}$ & $\begin{array}{l}\text { Almizaraque (Almizaraque), Campos (Cueva del } \\
\text { Almanzora), Cortijo de Baladrar (Macenas), } \\
\text { Cortijo del Molino de la Higuera (Los Galardos), } \\
\text { Cuartillas (Cuevas del Almanzora), La Losa } \\
\text { (Turre), Las Pilas de Mojácar (Mojácar), Los Silos } \\
\text { de Vera (Vera), Zajara (Cuevas del Almanzora) }\end{array}$ \\
\hline Cádiz & $\begin{array}{l}5 \text { yacimientos, } \\
87 \text { muestras }\end{array}$ & $\begin{array}{l}\text { Dolmen de Alberite (Villamartín), El Retamar } \\
\text { (Puerto Real), El Rinconcillo (Algeciras), Torre de } \\
\text { Doña Blanca (Puerto de Santa María), Venta del } \\
\text { Carmen (Los Barrios) }\end{array}$ \\
\hline Córdoba & $\begin{array}{l}7 \text { yacimientos, } \\
77 \text { muestras }\end{array}$ & $\begin{array}{l}\text { Córdoba (Córdoba), El Llanete de los Moros } \\
\text { (Montoro), Hacho de Benamejí (Benamejí), La } \\
\text { Muela de Santaella (Santaella), Laderas de Morana } \\
\text { (Lucena), Madinat Al-Zahra (Córdoba), Montur- } \\
\text { que (Monturque) }\end{array}$ \\
\hline Granada & $\begin{array}{l}18 \text { yacimientos, } \\
213 \text { muestras }\end{array}$ & $\begin{array}{l}\text { Cueva de la Carigüela (Piñar), Cueva de la Mujer } \\
\text { (Alhama de Granada), Cueva de la Ventana } \\
\text { (Piñar), Cueva de las Campanas (Gualchos), } \\
\text { Cueva de los Molinos (Alhama de Granada), } \\
\text { Cueva del Agua (Alhama de Granada), Cueva del } \\
\text { Agua de Prado Negro (Iznalloz), Cueva del } \\
\text { Capitán (Salobreña), Cueva del Conejo (Alhama } \\
\text { de Granada), Cueva del Coquino (Loja), Cueva del } \\
\text { Malalmuerzo (Moclín), La Molaina (Pinos } \\
\text { Puente), Las Majolicas (Alfacar), Loma de Ceres } \\
\text { (Molvízar), Poblado de los Castillejos (Montefrío), } \\
\text { Salobreña (Salobreña), Sima de los Intentos } \\
\text { Sima Rica (Alhama de Granada) }\end{array}$ \\
\hline Huelva & $\begin{array}{l}6 \text { yacimientos, } \\
90 \text { muestras }\end{array}$ & $\begin{array}{l}\text { Cabezo de San Pedro (Huelva), Cerro de San } \\
\text { Pedro (Huelva), El Trastejón (Zufre), Huelva } \\
\text { (Huelva), San Bartolomé de Almonte (Almonte), } \\
\text { Tejada la Vieja (Escacena la Vieja) }\end{array}$ \\
\hline Jaén & $\begin{array}{l}3 \text { yacimientos, } \\
77 \text { muestras }\end{array}$ & $\begin{array}{l}\text { Calañas de Marmolejo (Marmolejo), Cástulo } \\
\text { (Linares), Los Villares de Yújar (Yújar) }\end{array}$ \\
\hline Málaga & $\begin{array}{l}2 \text { yacimientos, } \\
18 \text { muestras }\end{array}$ & $\begin{array}{l}\text { Cerro de la Corona (Totalán), Cerro del Villar } \\
\text { (Guadalhorce) }\end{array}$ \\
\hline Sevilla & $\begin{array}{l}10 \text { yacimientos, } \\
214 \text { muestras }\end{array}$ & $\begin{array}{l}\text { Arva (Alcolea del Río), Astigi (Écija), Casa del } \\
\text { Marqués de Saltillo (Carmona), Cerro de la } \\
\text { Cabeza (Santiponce), Cerro Macareno (La Rin- } \\
\text { conada), Hospital de las Cinco Llagas (Sevi-lla), } \\
\text { La Traviesa (Almadén de la Plata), Plaza de Lasso } \\
\text { (Carmona), Sevilla (Sevilla), Valencina de la } \\
\text { Concepción (Valencina de la Concepción) }\end{array}$ \\
\hline TOTAL & $\begin{array}{l}60 \text { yacimientos } \\
976 \text { muestras }\end{array}$ & \\
\hline
\end{tabular}

Tab. 2. Lista de yacimientos por provincia y municipio. 


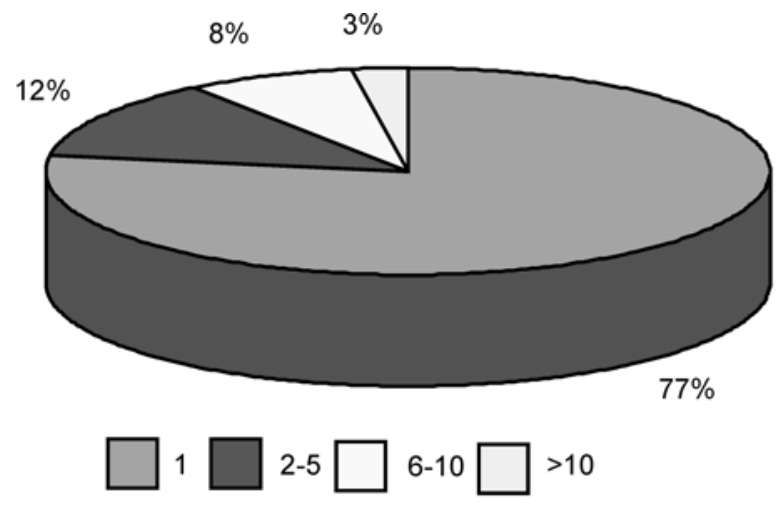

Fig. 6. Distribución porcentual del número de yacimientos por estudio (como porcentaje del número total de estudios).

yacimiento concreto o por otros factores (limitación de recursos para realizar muestreos más amplios), la mayor parte de los estudios de Arqueometría cerámica en Andalucía se caracterizan por el análisis de los materiales de un único yacimiento.

La cuestión de cuando y por qué se buscan las técnicas arqueométricas de análisis es probablemente crucial para entender esta observación. Como se indicó anteriormente, una gran proporción de estudios arqueométricos se publican como "apéndices" a los informes de excavación, cuyos resultados son a menudo base para artículos subsiguientes o comunicaciones y ponencias aparecidas en actas de conferencias. Por lo que se refiere a los informes de excavación, el punto hasta el que resulta acertada la aplicación de técnicas arqueométricas varía, tal como pasa con la integración de los resultados en la interpretación arqueológica final. En muchos casos, los resultados arqueométricos se usan meramente para confirmar las observaciones cronológicas, tipológicas o estratigráficas, y no dan lugar a la apertura de nuevas líneas innovadoras de investigación. La caracterización de la fábrica o textura de los restos es un tema central en los estudios de arqueometría cerámica en los que los análisis de una pequeña selección de fragmentos parecen reemplazar a la descripción visual detallada de colecciones completas posterior a la excavación. Puede decirse, por tanto, que, con contadas excepciones (por ejemplo Contreras Cortés et al. 1988), hay una cierta utilización de la Arqueometría como "alternativa" (cientifista) a la clasificación morfológica (normalmente no formalizada por medio de métodos estadísticos) más que como un complemento o vía de contrastación de ésta o de desarrollo de nuevos temas y estrategias de estudio.

\subsection{Caracterización crono-funcional de los yacimientos}

Un aspecto de gran importancia para entender el impacto que la aqueometría de materiales cerámicos ha tenido en la Arqueología andaluza es, evidentemente, la caracterización crono-funcional de los yacimientos de los que proceden las muestras. Estos datos (Tab. 3) tienen la potencialidad de informar no solo del diferencial impacto que las ciencias exactas están teniendo dentro de las diferentes tradiciones internas de la Arqueología, sino también de la naturaleza del conocimiento que este proceso está generando.

En lo que se refiere a la cronología (Tab. 4 y Figs. 7 y 8), es significativo que cerca de tres cuartas partes de las muestras examinadas pertenecen a materiales de yacimientos prehistóricos $(51 \%)$ o protohistóricos $(20 \%)$, mientras que exactamente el $25 \%$ son de época romana y apenas un $5 \%$ de épocas medieval, moderna o contemporánea. La distribución porcentual de las localizaciones arqueológicas dentro del inventario andaluz de yacimientos arqueológicos (3), muestra que los yacimientos de la Prehistoria Reciente suponen un 18,15\% del total, por lo que claramente la Arqueometría cerámica es aplicada al estudio de estos sitios bastante por encima de la representación numérica que les corresponde dentro del registro arqueológico andaluz. En cambio, los yacimientos romanos suponen casi la mitad $(49,34 \%)$ de los yacimientos arqueológicos documentados (oficialmente) en la actualidad en Andalucía, por lo cual, el hecho de que tan solo el $25 \%$ de las muestras cerámicas analizadas mediante métodos arqueométricos sean de cronología romana supone una importante sub-representación de este segmento cronológico del registro. Más acusado es el caso de los sitios de cronología medieval, que representan actualmente el 20,16\% del inventario andaluz de yacimientos arqueológicos, mientras que las muestras cerámicas analizadas arqueométricamente sólo alcanzan el $2 \%$ del total. Por otro lado, los datos registrados para la muestra andaluza no coinciden con los obtenidos por García Heras al evaluar la producción bibliográfica de Arqueometría cerámica a nivel nacional (Tab. 5), donde, al menos por número de estudios publicados, la época romana es la más representada. En

(3) Información disponible en la base de datos en línea de Bienes Inmuebles del Instituto Andaluz del Patrimonio Histórico de la Consejería de Cultura de la Junta de Andalucía: www.juntadeandalucia.es/cultura/iaph/infopha/04bd/index.htm 


\section{CARACTERIZACIÓN CRONO-FUNCIONAL}

Asentamientos neolíticos (21)

Lugares funerarios neolíticos (2)

Asentamientos de la Edad del Cobre (8)

Asentamientos de la Edad del Bronce (9)

\begin{tabular}{l}
\hline $\begin{array}{l}\text { Lugares funerarios de la Edad del } \\
\text { Bronce (1) }\end{array}$ \\
\hline
\end{tabular}

Asentamientos de la Edad del

Hierro (16)

\section{Asentamientos romanos (5)}

Lugares producción romanos (6)

\begin{tabular}{l}
\hline Asentamientos medievales (1) \\
\hline $\begin{array}{l}\text { Asentamientos modernos y } \\
\text { contemporáneos (1) }\end{array}$ \\
\hline
\end{tabular}

\section{YACIMIENTOS}

Almizaraque, Campos, Cuartillas, Cueva de la Carigüela, Cueva de la Mujer, Cueva de la Ventana, Cueva de las Campanas, Cueva de los Molinos, Cueva del Agua, Cueva del Agua del Prado Negro, Cueva del Capitán, Cueva del Conejo, Cueva del Coquino, Cueva del Malalmuerzo, El Retamar, La Molaina, Las Majolicas, , Los Silos de Vera, Sima de los Intentos, Sima Rica, Poblado de los Castillejos Cerro de la Corona, Dolmen de Alberite Almizaraque, Campos, Cortijo de Baladrar, Cortijo del Molino de la Higuera, La Losa, Las Pilas de Mojácar, Monturque, Zajara

Cabezo de San Pedro, Cerro de San Pedro, Cerro Macareno, El Trastejón, El Llanete de los Moros, La Muela de Cástulo, La Muela de Santaella, Monturque, San Bartolomé de Almonte

\section{La Traviesa}

Calañas de Marmolejo, Casa del Marqués de Saltillo, Cástulo, Cerro de la Cabeza, Cerro del Villar, Cerro Macareno, Hacho de Benamejí Huelva, Laderas de Morana, La Muela de Santaella, Llanete de los Moros, Monturque, San Bartolomé de Almonte, Tejada la Vieja Torre de Doña Blanca, Valencina de la Concepción Arva, Astigi, Cástulo, Córdoba, Salobreña El Rinconcillo, Hospital de las Cinco Llagas, Loma de Ceres, Los Villares de Yújar, Plaza de Lasso, Venta del Carmen Madinat Al-Zahra Sevilla

Tab. 3. Caracterización crono-funcional de los yacimientos incluidos en el estudio.

\begin{tabular}{|l|c|c|c|}
\hline CRONOLOGÍA & $\begin{array}{c}\text { NÚMERO DE } \\
\text { MUESTRAS }\end{array}$ & $\begin{array}{c}\text { NÚMERO DE } \\
\text { YACIMIENTOS }\end{array}$ & $\begin{array}{c}\text { MEDIA DE } \\
\text { MUESTRAS POR } \\
\text { YACIMIENTO }\end{array}$ \\
\hline Neolítico & 363 & 23 & 16 \\
\hline Edad del Cobre & 40 & 8 & 5 \\
\hline Edad del Bronce & 90 & 10 & 9 \\
\hline Edad del Hierro & 197 & 16 & 22 \\
\hline Época Romana & 240 & 11 & - \\
\hline Época medieval & 16 & 1 & - \\
\hline $\begin{array}{l}\text { Época Moderna y } \\
\text { contemporánea }\end{array}$ & 30 & 1 & \\
\hline
\end{tabular}

Tab 4. Número de muestras y yacimientos por período cronológico. 


\begin{tabular}{|l|l|}
\hline \multicolumn{1}{|c|}{$\begin{array}{c}\text { ANDALUCÍA 1979-2002 } \\
\text { (Número de muestras) }\end{array}$} & \multicolumn{1}{c|}{$\begin{array}{c}\text { ESPAÑA 1972-1995 } \\
\text { (Número de estudios) }\end{array}$} \\
Clasificación de García Heras (1997: 131)
\end{tabular}

Tab. 5. Tabla comparativa del interés suscitado por cada período cronológico en Andalucía y en España.

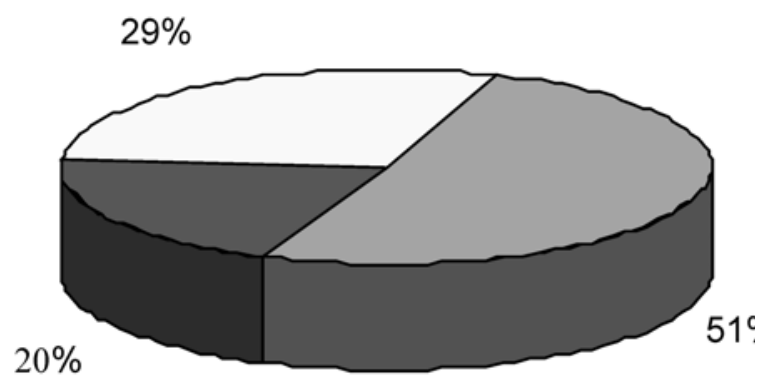

\section{Prehistoria $\quad \square$ Protohistoria $\square$ Historia}

Fig. 7. Cronología general de las muestras.

conjunto, ello sugiere que en Andalucía se da una mayor apertura a la aplicación de los métodos físico-químicos por parte de la investigación prehistórica que por parte de la Arqueología clásica. Ello coincide bastante con los datos obtenidos en un análisis bibliométrico llevado a cabo hace una década que revelaba un perceptible desfase en la configuración epistemológica y teórico-metodológica de la Arqueología clásica andaluza, definida de forma predominante como estudio formal y estilístico de los productos artísticos de las élites antiguas (Fernández Cacho y García Sanjuán 1995). En el caso de la Arqueología medieval y postmedieval, el pequeño número de muestras cerámicas estudiadas podría encontrar una explicación si cabe más sencilla en el escaso impacto que la Arqueología todavía tiene en el estudio de estos periodos históricos. El número muy bajo de muestras medievales es

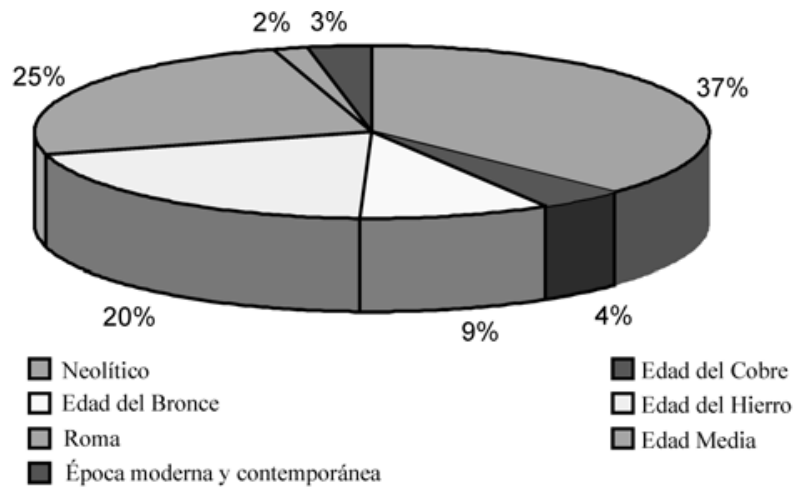

Fig. 8. Cronología específica de las muestras (como porcentaje del número total de muestras $(\mathrm{N}=976)$.

particularmente sorprendente dada la riqueza de restos materiales de este periodo a lo largo de toda Andalucía (en particular del periodo islámico) y deja traslucir asimismo una falta de renovación y actualización metodológica en el campo del medievalismo andaluz.

Dentro de las muestras prehistóricas, destaca especialmente el hecho de que el $75 \%$ están datadas en el Neolítico, mientras que apenas el 13\% corresponden a la Edad del Cobre y la Edad del Bronce y el 20\% son de la Edad del Hierro (Fig. 8). Este notorio predominio de los materiales cerámicos del Neolítico en comparación con los de Edad del Bronce, del Cobre y del Hierro no se corresponde con el interés suscitado por ese periodo a escala nacional (Tab. 5) y en el caso de Andalucía obedece al fuerte peso numérico que tiene el estudio de M. S. Navarrete Enciso et al. (1991) sobre materia- 


\begin{tabular}{|l|c|c|c|r|}
\hline PERIODO & ASENTAMIENTOS & $\begin{array}{c}\text { LUGARES } \\
\text { FUNERARIOS }\end{array}$ & $\begin{array}{c}\text { LUGARES } \\
\text { PRODUCCIÓN }\end{array}$ & TOTAL \\
\hline Neolítico & $356(21)$ & $7(2)$ & 0 & 363 \\
\hline Edad del Cobre & $40(8)$ & 0 & 0 & 40 \\
\hline Edad del Bronce & $79(9)$ & $11(1)$ & 0 & 90 \\
\hline Edad del Hierro & $197(16)$ & 0 & 0 & 197 \\
\hline Época Romana & $89(5)$ & 0 & $151(6)$ & 240 \\
\hline Época Medieval & $16(1)$ & 0 & 0 & 16 \\
\hline $\begin{array}{l}\text { Época Moderna y } \\
\text { Contemporánea }\end{array}$ & 0 & 0 & $30(1)$ & 30 \\
\hline Total & 777 & 18 & 181 & 976 \\
\hline
\end{tabular}

Tab. 6. Número de muestras por categoría crono-funcional del sitio de procedencia (entre paréntesis el número de yacimientos).

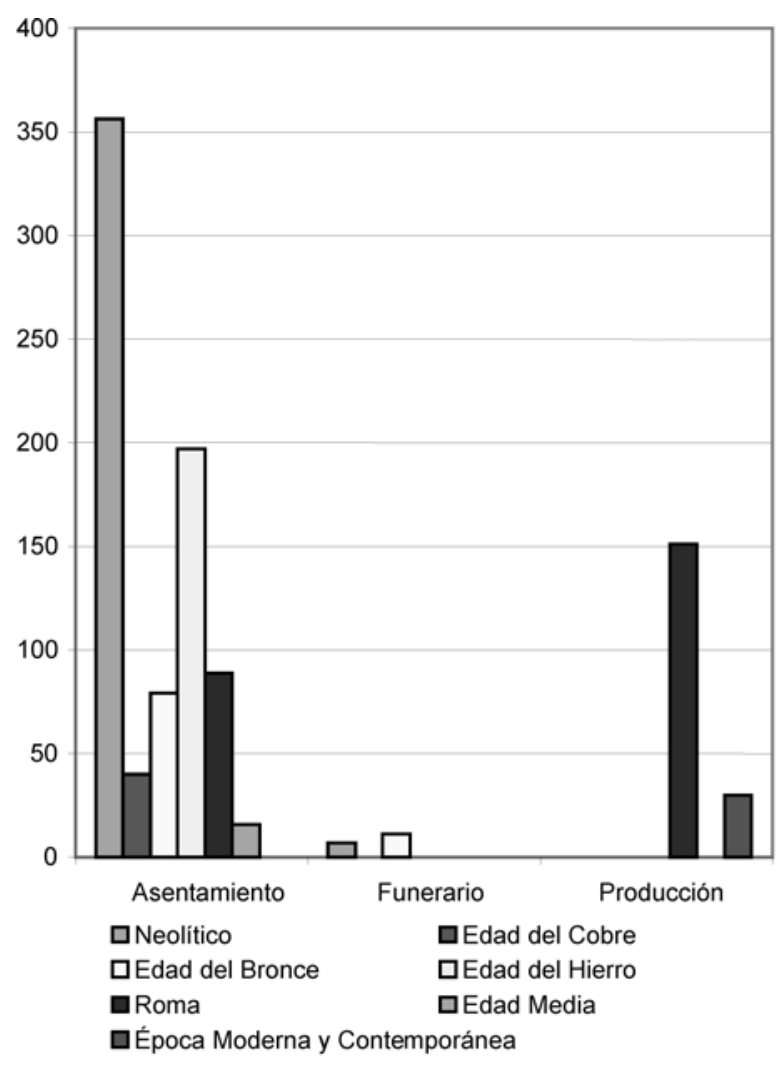

Fig. 9. Recuento de muestras por tipo de yacimiento.

les cerámicos neolíticos de la provincia de Granada.

En lo que se refiere a la caracterización funcional de los yacimientos, la gran mayoría de muestras (en torno al $80 \%$ del total) proceden de sitios de carácter habitacional (cuevas con ocupación humana, poblados, ciudades, etc.) (Tab. 6 y Figs. 9 y 10). El segundo grupo más numeroso (con un 19\%) per-

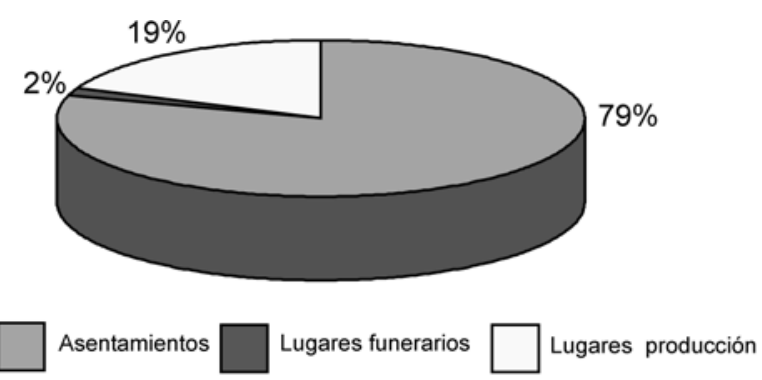

Fig. 10. Distribución porcentual de muestras por tipo de yacimiento.

tenece a materiales recogidos de espacios productivos, especialmente hornos de cerámica de época romana o moderna (es notable la ausencia en este grupo de muestras de cronología medieval). Finalmente, la categoría de sitios de carácter funerario aparece extraordinariamente sub-representada en el conjunto de la muestra, con apenas 3 sitios y un raquítico recuento de 18 muestras (2\% del total), lo cual aparece subrayado por la completa ausencia de muestras procedentes de sitios de carácter ritual o cultual (por ejemplo vasijas o terracotas votivas). De hecho, en la muestra aquí estudiada no existe ni un solo caso de materiales cerámicos de contextos funerarios romanos. Esta destacada inferioridad cuantitativa de los materiales del registro funerario (de cualquier época) frente a los del registro habitacional no se corresponde con la gran importancia que han tenido en la Arqueología andaluza los estudios de necrópolis y monumentos funerarios. Una explicación de esta acentuada tendencia podría ser que los artefactos cerámicos procedentes de contextos funerarios presentan a menudo un buen grado de conservación, por lo que tradicionalmente se les ha 


\begin{tabular}{|l|c|c|c|}
\hline PERIODO & ASENTAMIENTOS & $\begin{array}{c}\text { LUGARES } \\
\text { FUNERARIOS }\end{array}$ & $\begin{array}{c}\text { LUGARES } \\
\text { PRODUCCIÓN }\end{array}$ \\
\hline Neolítico & 17 & 3,5 & - \\
\hline Edad del Cobre & 5 & - & - \\
\hline Edad del Bronce & 9 & 11 & - \\
\hline Edad del Hierro & 12 & - & - \\
\hline Época Romana & 18 & - & - \\
\hline Época Medieval & 16 & - & 30 \\
\hline Época Moderna y Contemporánea & - & - & \\
\hline
\end{tabular}

Tab. 7. Media de las muestras por tipo de sitio y por período.

atribuido un mayor valor museológico. Quizás por esta razón algunos/as arqueólogos/as hayan sido más renuentes a aplicarles métodos físico-químicos de estudio que con frecuencia (aunque desde luego no siempre) tienen un carácter destructivo.

En términos de la media de muestras por categoría funcional y cronología del yacimiento de origen (Tab. 7), son, como ya se ha señalado antes, los sitios de tipo funerario (prehistóricos, antiguos o medievales) los que presentan las cifras más bajas, reflejando una cobertura de los materiales muy pobre. En este ámbito, la Arqueometría cerámica andaluza tiene evidentemente mucho espacio para mejorar. En contraste, los valores medios más elevados corresponden a lugares de ocupación y producción alfarera de época romana, lo cual no deja de suponer una cierta paradoja, ya que los materiales cerámicos romanos presentan un mayor grado de estandarización y menor variabilidad, por lo que, al menos en teoría, los estudios podrían basarse en un número menor de muestras. Los materiales cerámicos prehistóricos que, en cambio, presentan una mayor diversidad en términos de materias primas, fabricación y tecnología, requerirían muestras más numerosas para analizar tal variabilidad.

En conjunto, a partir de los datos sobre caracterización cronológico-funcional de los yacimientos se pueden hacer tres constataciones relevantes. En primer lugar, parece existir una pauta de asociación entre el periodo estudiado y el carácter funcional de los sitios de los que proceden las muestras: a los/as especialistas en las sociedades hispanorromanas parecen interesarle los estudios de Arqueometría cerámica de muestras procedentes sobre todo de asentamientos o alfares, pero no los de cerámicas funerarias (ello quizás refleje el fuerte interés que suscita entre los/as especialistas en Arqueología romana andaluza el tema del comercio en envases anfóricos). Igualmente, a los especialistas en las edades del Cobre y del Bronce no les ha interesado apenas el ámbito de la cerámica funeraria.

En segundo lugar, es significativo y quizás preocupante que ni una sola de las publicaciones trate de materiales procedentes de diferentes tipos de contextos funcionales (ni siquiera dentro de un yacimiento único), para, por ejemplo, comparar la naturaleza de las cerámicas utilizadas en actividades propias de la vida diaria (almacenamiento, cocinado, consumo, transporte) con las empleadas como ofrendas funerarias, o para explorar posibles asociaciones entre las cerámicas de alfares concretos con la alfarería del ámbito doméstico. De hecho, el único trabajo que, hasta donde sabemos, aborda este tipo de enfoque comparativo, acaba de salir publicado por nosotros mismos (Polvorinos del Río et al. 2005).

En tercer lugar, se detecta una importante desconexión entre los análisis de materiales y los análisis tipológico-tipométricos. Debido a las condiciones de formación del registro de asentamientos (básicamente desechos y detritus), los materiales cerámicos procedentes de esos lugares de habitación, para los cuales abundan los estudios de caracterización físico-química, están muy fragmentados y por tanto constituyen un pobre indicador para el estudio de la morfología de los recipientes cerámicos. Por su parte, los recipientes cerámicos procedentes de contextos funerarios, que suelen constituir una mejor base para el estudio morfológico-morfométrico por su mejor estado de conservación (son depositados como ofrendas votivas), no están siendo objeto de estudios arqueométricos. Como resultado, se está dificultando (o imposibilitando) una verdadera perspectiva múltiple que aborde simultáneamente la función, forma y tecnología de los artefactos cerámicos. De hecho, tan solo un estudio en todo el 
conjunto bibliográfico estudiado, concretamente el de F. Contreras Cortés et al. de los materiales de la Edad del Bronce del yacimiento de Cuesta del Negro (Purullena, Granada) aborda de una forma robusta la comparación de aspectos morfológicos y arqueométricos para un mismo conjunto cerámico.

\subsection{Técnicas y métodos de análisis}

Otro aspecto tenido en cuenta en esta evaluación de la Arqueometría cerámica andaluza es el de la aplicación de las distintas técnicas de análisis (composición, procedencia de materias primas, cuestiones tecnológicas, dataciones, etc.) al objeto de intentar identificar pautas en su utilización o en los principales temas a los que han sido aplicadas, buscando asimismo posibles tendencias en su evolución a lo largo del tiempo. De cara a simplificar el recuento y presentación de los datos, se han distinguido entre tres posibles categorías de técnicas, mineralógicas, de composición química y de propiedades físicas, cada una de las cuales proporciona información sobre un aspecto particular de las cerámicas arqueológicas (Barclay 2001). La frecuencia relativa de este amplio grupo de técnicas se ha registrado junto a los detalles de las técnicas individuales aplicadas (Tab. 8 y Figs. 11 y 12).

Las técnicas de caracterización mineralógica son, con mucho, las más aplicadas, representando aproximadamente el 56\% de los análisis llevados a cabo. Las tres técnicas más frecuentemente aplicadas (observación visual y microscópica, difracción de rayos $\mathrm{X}$ y petrografía de láminas delgadas) pertenecen a este grupo. La difracción de rayos $\mathrm{X}$ aparece aplicada en todos los estudios aquí considerados excepto dos, lo que la distingue como la técnica de caracterización mineralógica más universalmente utilizada. La aplicación del método de Rietveld para el análisis cuantitativo de fases mineralógicas y de la amorfa de muestras cerámicas aún es muy escasa. Por otro lado el uso de la DRX no viene siempre acompañado del correspondiente estudio de láminas delgadas, una técnica capaz de proporcionar una información mineralógica y textural de gran relevancia. Dentro del grupo de las técnicas mineralógicas, el uso de la espectrometría de infrarrojo es mucho menos frecuente. El segundo grupo (30\% del total) está formado por técnicas de análisis de composición química como espectrometría de absorción atómica, espectrometría por fluorescencia de rayos $\mathrm{X}$ o espectrometría de emisión atómica con plasma acoplado por inducción, mientras que el análisis de activación neutrónica y la espectrometría con radiación ultravioleta/visible aparecen en menos estudios. Las técnicas de caracterización de propiedades físicas (14\%), que incluye análisis térmico, porosidad, densidad, caracterización cromática y propiedades físicas, parecen ser menos utilizadas.

Por lo que se refiere a la combinación de técnicas, en principio es positivo constatar que sólo un número pequeño de estudios aplica una sola técnica, normalmente la difracción de rayos X. Sin embargo (siguiendo los grupos de técnicas detallados en la tabla 8), en torno de una cuarta parte de los estudios de la muestra aplican solo técnicas de caracterización mineralógica, sin el apoyo del análi-

\begin{tabular}{|l|l|l|}
\hline \multicolumn{1}{|c|}{$\begin{array}{c}\text { COMPOSICIÓN } \\
\text { MINERALÓGICA }\end{array}$} & \multicolumn{1}{c|}{$\begin{array}{c}\text { COMPOSICIÓN } \\
\text { QUIMMICA }\end{array}$} & \multicolumn{1}{c|}{$\begin{array}{c}\text { PROPIEDADES } \\
\text { FÍSICAS }\end{array}$} \\
\hline - Difracción de Rayos-X & - Fluorescencia de Rayos X & - Análisis térmico \\
- Observación macroscópica & - Microscopía electrónica de & - Porosidad \\
o microscópica de baja & barrido & - Densidad \\
amplificación & - Espectrometría por absorción & - Caracterización \\
- Promática \\
- Petrografía de láminas & atómica & \\
delgadas & - Espectrometría de emisión & \\
- Espectrometría de infrarrojos & atómica por plasma acoplado & \\
& por inducción & \\
& - Análisis de activación & \\
& neutrónica & \\
& - Espectrometría con rayos \\
& ultravioleta y/o luz visible & \\
\hline
\end{tabular}

Tab. 8. Lista de técnicas aplicadas a las muestras incluidas en el estudio. 


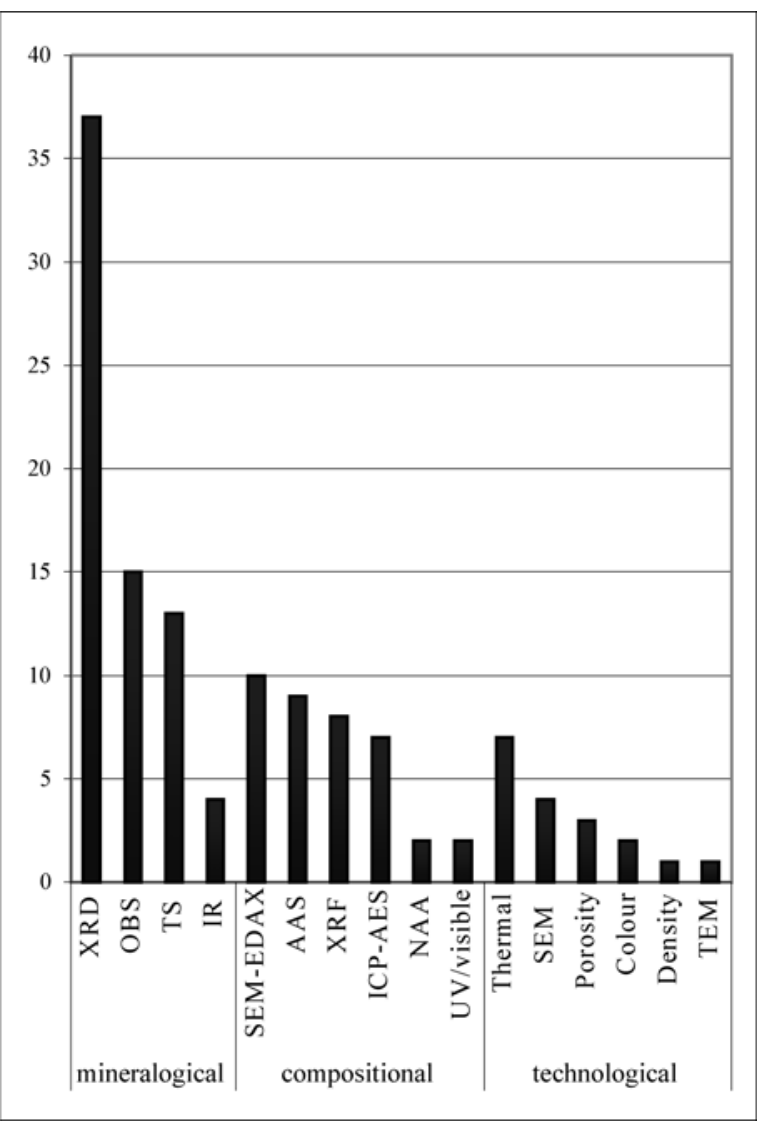

Fig. 11. Recuento de técnicas analíticas por grupo (mineralógicas, compositivas y tecnológicas) y número de aplicaciones.

sis de composición química y de propiedades físicas. Aproximadamente el $40 \%$ de los estudios combinan técnicas de caracterización mineralógica y compositiva, mientras que el $26 \%$ combinan las técnicas de los tres grupos.

Finalmente, se ha intentado evaluar la evolución de la frecuencia de empleo de las principales técnicas mineralógicas y compositivas en el periodo entre 1983 y 2002 . Al haberse registrado, por cada periodo de cinco años, un número de estudios diferentes, y por tanto un número variable de casos de empleo de las distintas técnicas (proporcional al número de estudios publicados), la frecuencia de empleo de las diferentes técnicas ha sido presentada como un índice (número de empleos/número de estudios) para reflejar la importancia relativa de los métodos individuales (Fig. 13). Este índice tiene, naturalmente, un valor máximo de 1 en aquellos casos en que, dentro de un periodo dado, una técnica concreta ha sido empleada en todos los estudios.

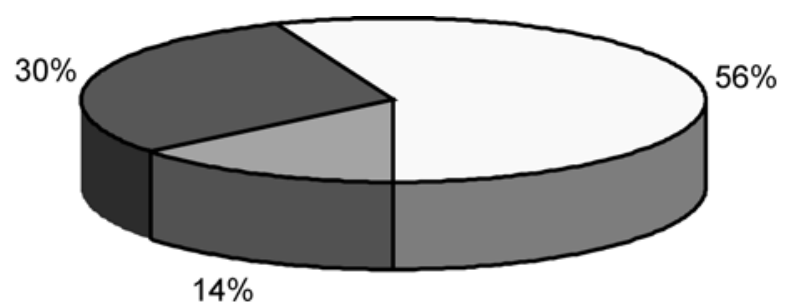

tecnológicas $\square$ compositivas $\square$ mineralógicas

Fig. 12. Distribución porcentual de los tres principales grupos de técnicas.

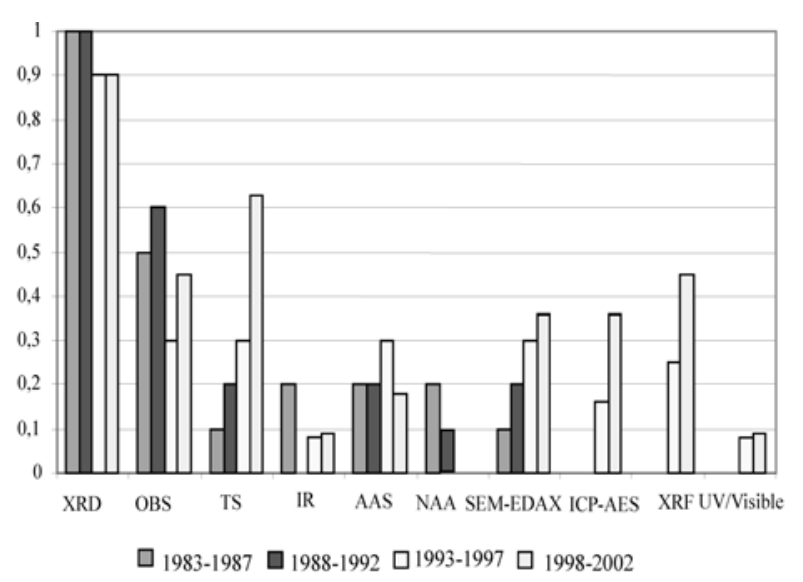

Fig. 13. Evolución de la frecuencia de empleo de las principales técnicas mineralógicas y compositivas.

Es, por ejemplo, el caso de la difracción de rayos X en los periodos 1983-1987 y 1988-1992. De hecho, la difracción de rayos-X se confirma como la técnica más importante de la Arqueometría cerámica independientemente del año de publicación, siendo aplicada en prácticamente todos los artículos de nuestra muestra (excepto dos). Las técnicas como la petrografía de lámina delgada y microscopía de barrido electrónico despliegan una marcada progresión a lo largo del período del estudio, aunque entendemos que la potencialidad de la primera no ha sido lo suficientemente valorada. En el extremo contrario tenemos el análisis por activación neutrónica, que aparece utilizado de forma puntual en la segunda mitad de los 1980 para cerámicas prehistóricas de Valencina de la Concepción (Sevilla) (González Vilches et al. 1988) y para el estudio de las excepcionales cerámica micénicas de Llanete de los Moros (Montoro, Córdoba) (Mommsen et al. 1990; Martín de la Cruz, 1990), sin que haya teni- 
do luego presencia o continuidad en los estudios de Arqueometría cerámica andaluza. Otras técnicas como la fluorescencia de rayos X, la de la espectrometría de plasma acoplado inductivamente y la espectrometría de infrarrojos se introdujeron en la década de los noventa.

\section{CONCLUSIONES}

A partir de la información referida en las secciones precedentes es posible plantear algunas valoraciones relativas a la relación entre la Arqueología y la Ciencia de Materiales en Andalucía y, por extensión, en España.

1) En el periodo estudiado se detecta un claro y sostenido aumento del número de publicaciones científicas en este campo, lo que revela la génesis y establecimiento de un campo de investigación que hace 20 años era casi inexistente en nuestro país. Algunos indicios, sin embargo, sugieren que este proceso es insuficiente e irregular. Por un lado, la distribución de publicaciones por año (de por sí bastante limitada), es bastante variable, dependiendo mucho de la ocasional publicación de actas de congresos, lo que sugiere que no hay una producción bibliográfica constante y fluida. Además, una buena parte de las publicaciones se dan como parte de memorias e informes de excavaciones arqueológicas donde la Arqueometría (como otros estudios de carácter multidisciplinar, por ejemplo arqueozoológicos o arqueobotánicos) ha sido a menudo relegada a una peculiar sección de "apendices" (supuestamente "técnicos" o "científicos") que parece llevar implícita la noción de que el estudio de materiales no es algo intrínsecamente arqueológico, lo cual, dentro del viejo debate relativo a la configuración epistemológica de la Arqueología (Vila i Mitjà y Estévez Escalera 1989:274) supone un enfoque que empobrece enormemente el futuro de la/s ciencia/s arqueológica/s.

2) La distribución geográfica (por provincias) de los yacimientos arqueológicos de los que proceden las muestras estudiadas es irregular, con presencia predominante (por número de muestras y yacimientos estudiados) de las provincias que albergan los dos centros universitarios principales de la comunidad autónoma (Sevilla y Granada), o que se han visto influidas por la investigación desarrollada desde uno de ellos (Almería). Otro hecho constatado, e interesante a nivel epistemológico en relación con el contexto geográfico y territorial de los estu- dios, es que la gran mayoría de las publicaciones abordan el estudio de muestras de un yacimiento único, sin incluir valoraciones comparativas (de carácter diacrónico o sincrónico) con otros yacimientos o (por ejemplo) con muestras procedentes de depósitos de arcilla.

3) La gran mayoría (tres cuartas partes) de los estudios de Arqueometría cerámica andaluza tratan de materiales prehistóricos o protohistóricos, mientras que los de época romana (una cuarta parte) se encuentran bastante por debajo, y los de época medieval o post-medieval son muy minoritarios. Dada la distribución relativa de los yacimientos de estos grandes bloques cronológicos en el registro arqueológico andaluz, ello supone una sobre-representación de los materiales prehistóricos y una subrepresentación de los de época clásica. Este desequilibrio podría explicarse como producto de ciertas diferencias en la configuración disciplinar entre la Arqueología prehistórica y la Arqueología clásica, donde la primera es más receptiva a las innovaciones de carácter científico por su mayor vinculación con las ciencias naturales y medioambientales. El bajo número de estudios de materiales cerámicos medievales se corresponde perfectamente con el escaso desarrollo que la propia Arqueología medieval tiene en la comunidad autónoma andaluza.

4) En lo que se refiere a la naturaleza funcional de los yacimientos de los que proceden las muestras estudiadas, se han detectado igualmente algunas tendencias significativas. Por una parte hay un masivo predominio de materiales cerámicos procedentes de contextos de asentamiento y una equivalente sub-representación de materiales hallados en contextos funerarios, con un porcentaje intermedio de muestras procedentes de lugares de producción (esencialmente alfares). Similarmente, son prácticamente inexistentes los trabajos que aportan una comparación sistemática de muestras procedentes de distintos contextos funcionales, buscando posibles diferencias tecnológicas entre las cerámicas utilizadas para distintas funciones (almacenamiento, cocinado, transporte, metalurgia, ajuares funerarios, etc.). En conjunto, la gran mayoría de las publicaciones incluidas en este estudio incluyen algunos datos básicos de contextualización arqueológica de las muestras, tales como nombre, situación geográfica y clasificación cronológica y funcional básica del yacimiento, número de muestras estudiadas, asociaciones de materiales arqueológicos, etc. Ejemplos como el trabajo de Mosquera 
Díaz et al. (2001), sobre aplicación de porosimetría de intrusión de mercurio a cerámicas de cronología tartésica, donde ni tan siquiera se cita el nombre del yacimiento del que proceden las muestras, son raros. Sin embargo, pocos estudios proporcionan una verdadera profundidad de detalle sobre los contextos de los que proceden las muestras (arquitectura, estratigrafía, asociaciones artefactuales), lo cual supone un cierto riesgo de desconexión entre la lectura arqueométrica de los materiales prehistóricos y antiguos y sus respectivos contextos arqueológicos. Igualmente, se detecta una cierta tendencia a limitar las publicaciones a una descripción empírica de los resultados analíticos, abordando solo superficialmente (o no abordándola en absoluto) la significación de los materiales dentro de su contexto cultural.

5) La presentación explícita de la estrategia de investigación y muestreo, así como el conjunto de problemas a que se pretende dar respuesta (es decir, los objetivos específicos de los análisis de arqueometría), es bastante infrecuente, lo cual constituye una de las principales debilidades del conjunto de publicaciones evaluadas. En contraste, los procedimientos técnicos de los análisis son generalmente bien detallados en las publicaciones, reflejando así más preocupación por las técnicas de análisis que por el armazón teórico y metodológico dentro del cual son aplicadas. Las técnicas de caracterización mineralógica son las más empleadas con diferencia (56\% de los estudios), seguidas por el grupo de técnicas de análisis de composición química (30\%) mientras que las que hemos denominado de caracterización de propiedades físicas son más minoritarias $(14 \%)$. Naturalmente se observa una importante pauta de evolución temporal en las técnicas, según han ido siendo perfeccionadas: la difracción de rayos X constituye una técnica de aplicación casi universal, mientras que otras técnicas como la fluorescencia de rayos $\mathrm{X}$, la espectrometría de plasma acoplado inductivamente y la espectrometría de infrarrojos aparecen más recientemente a partir de la década de los 90, en función del incremento de la disponibilidad de instalaciones científicas en los medios universitarios. La petrografía de lámina delgada, en cambio, constituye un ejemplo de infrautilización recurrente de una técnica de gran interés y potencial analítico.

En general, la conclusión de este estudio es que la arqueometría de materiales cerámicos ha experimentado un notable crecimiento dentro de la Arqueología andaluza, aunque dista de estar consoli- dada dentro del cuerpo disciplinar, presentando problemas importantes. Posiblemente, el más insoslayable de estos problemas es la existencia de una coordinación bastante pobre entre el análisis arqueométrico de los materiales cerámicos y la interpretación resultante en cuanto a pautas de conducta humana (es decir, aprovechamiento de recursos, procesos y técnicas de trabajo y manufactura, variabilidad funcional, intercambio de artefactos acabados, significado social, ideológico y simbólico de los objetos, variabilidad espacial y temporal, etc.). Muestreos numéricamente insuficientes, descontextualización territorial, inexistencia de análisis comparativos de contextos funcionales múltiples y descriptivismo generalizado son algunas de las manifestaciones de este problema.

Este desfase entre Arqueometría y Arqueología podría en parte justificarse o explicarse por la relativa "juventud" de la colaboración entre científicos/ as y arqueólogos/as dentro de la Arqueología andaluza (y posiblemente española por extensión). Pero creemos que ello supondría incurrir en un exceso de autocomplacencia. La realidad es que existe una incomunicación entre la (in)definición de los problemas a resolver arqueológicamente (en términos de comportamiento social), y el empleo de un sofisticado arsenal de técnicas físico-químicas con las cuales los/as arqueólogos/as no están demasiado familiarizados. Los problemas arqueológicos aparecen, con frecuencia, pobremente formalizados (o formulados) en términos teóricos y metodológicos, sin que se definan las implicaciones contrastadoras de las hipótesis planteadas y las subsiguientes posibilidades de corroboración de acuerdo con el alcance y limitaciones de datos y técnicas científicas. Por ello, como ya se ha dicho (Ramos Muñoz et al. 1997:225), existe un cierto riesgo de que la arqueometría se esté utilizando dentro de la Arqueología andaluza como ropaje con el que revestir (ocasionalmente) de un cientifismo más aparente que real una Arqueología tradicional más centrada en los objetos que en las vidas de los seres humanos y poco dispuesta a formalizar (y enriquecer) sus estrategias de investigación.

Esperamos que las constataciones formuladas en las páginas precedentes contribuyan a una reflexión cualificada sobre uno de los procesos de renovación más profundos e irreversibles que ha experimentado la Arqueología en su breve historia, un proceso que probablemente nos conduzca en el futuro a un noción epistemológica amplia y enriquecedora de nuestra disciplina: el de ciencias arqueológicas. 


\section{BIBLIOGRAFÍA}

AGUILERA MARTÍN, A. 1998: “Análisis multivariable: una nueva vía para la caracterización cerámica". Pyrenae 29: 117-134.

ANDERSON, J. (ed.) 1988: Scientific Analysis in Archaeology. Los Angeles. UCLA Institute of Archaeology.

ANDREWS, K. y DOONAN, R. 2003: Test Tubes and Trowels. Using Science in Archaeology. Stroud. Tempus.

BARCLAY, K. 2001: Scientific Analysis of Archaeological Ceramics. A Handbook of Resources. Oxford. Oxbow Books.

BARRIO MARTÍN, J. 1990 (ed.): Ciencia y Técnicas al Servicio de la Investigación Arqueológica (Madrid, 1217 de Noviembre de 1990). Madrid. Fundación Francisco Giner de los Ríos.

BENÉÍTEZ, P.; CALDERÓN, T. y MILLÁN, A. 1998: "Datación absoluta por termoluminiscencia: el horno del sector D". En D. Bernal Casasola (ed.): Excavaciones Arqueológicas en el Alfar Romano de la Venta del Carmen (Los Barrios, Cádiz): 325-328. Madrid. Universidad Autónoma de Madrid.

BENÉITEZ, P.; MILLÁN, M. A.; RAMOS MUÑOZ, J.; BERNAL CASASOLA, D. y CASTAÑEDA FERNÁNDEZ, V. 2004: "Datación absoluta por termoluminiscencia de material cerámico y de carbonatos procedentes del yacimiento arqueológico de la Cueva de Benzú (Ceuta)”. En M.J. Feliú Ortega et al. (eds.): Avances en Arqueometría 2003: 17-24. Cádiz. Universidad de Cádiz.

BERNAL CASASOLA, D. y PETIT DOMÍNGUEZ, M. D. 1999: "Análisis químico de resinas en ánforas romanas de vino y salazones de pescado: problemática y resultados”. En J. Capel Martínez (ed.): Arqueometría y Arqueología 269-294. Granada. Universidad de Granada.

BERNAL CASASOLA, D. y GARCÍA GIMÉNEZ, R. 1999: "Microfósiles en pastas cerámicas: viabilidad y potencialidad de su estudio aplicado a materiales arqueológicos". En J. Capel Martínez (ed.): Arqueometría y Arqueología 295-304. Granada. Universidad de Granada.

BLÁZQUEZ, J. M.; GARCÍA-GELABERT, M. P. y LÓPEZ PARDO, F. (eds.) 1985: Cástulo V. Excavaciones Arqueológicas en España 140. Madrid. Ministerio de Cultura.

BOWMAN, S. G. E. (ed.) 1991: Science and the Past. London. British Museum.

BUXEDA I GARRIGÓS, J. 1999: "Problemas en torno a la variación composicional”. En J. Capel Martínez (ed.): Arqueometría y Arqueología 305-322. Granada. Universidad de Granada.

CALDERÓN, T.; SIBILIA, E. y FERNÁNDEZ JURADO, J. 1989: "Datación absoluta por termoluminiscencia de materiales arqueológicos procedentes de Tejada la Vie- ja (Escacena del Campo) y Cabezo de San Pedro (Huelva)”. En J. Fernández Jurado (ed.): Tejada la Vieja. Una Ciudad Protohistórica. Huelva Arqueológica 9: 265281. Huelva. Diputación de Huelva.

CAÑABATE GUERRERO, M. L. 1998: Indicadores Químicos para la Arqueología. Jaén. Universidad de Jaén. CAÑABATE GUERRERO, M. L. y SÁNCHEZ VIZCAÍNO, A. 1995. "Análisis de indicadores bioquímicos del contenido de recipientes arqueológicos". Complutum 6: 281-291.

- 1999. "Identificación de grasas y ésteres de ceras en recipientes arqueológicos". Caesaraugusta 73: 319325.

CAPEL MARTÍNEZ, J. 1981: Estudio Mineralógico y Geoquímico de Sedimentos y Cerámicas Arqueológicas de Algunos Yacimientos de La Mancha. Tesis doctoral inédita. Granada. Universidad de Granada.

CAPEL MARTÍNEZ, J. (ed.) 1999: Arqueometría y Arqueología. Monográfica Arte y Arqueología. Granada. Universidad de Granada

CAPEL MARTÍNEZ, J. y DELGADO CALVO-FLORES, R. 1978: "Aplicación de métodos ópticos al estudio de cerámicas arqueológicas". Cuadernos de Prehistoria de la Universidad de Granada 3, 343-356.

CAPEL MARTÍNEZ, J.; LINARES GONZÁLEZ, J. y HUERTAS GARCÍA, F. 1979: "Métodos analíticos aplicados a cerámicas de la Edad del Bronce". Cuadernos de Prehistoria de la Universidad de Granada 4: 345-360.

CAPEL MARTÍNEZ, J.; DELGADO CALVO-FLORES, R.; PÁRRAGA, J. y PEÑA, J. A. 1990: "Modelo de una ficha descriptiva para el estudio de cerámicas arqueológicas por lámina delgada". Cuadernos de Prehistoria de la Universidad de Granada 14-15: 315-319.

CAPEL MARTÍNEZ, J.; DELGADO CALVO-FLORES, R.; PARRAGA, J. y GUARDIOLA, J. L. 1995: "Identificación de técnicas de manufactura y funcionalidad de vasijas cerámicas en estudios de lámina delgada". Complutum 6: 311-318.

CONTRERAS CORTÉS, F. 1985: Aplicación de Métodos Estadísticos y Analíticos a los Complejos Cerámicos de la Cuesta del Negro (Purullena, Granada). Tesis doctoral inédita. Granada. Universidad de Granada

CONTRERAS CORTÉS, F.; CAPEL MARTÍNEZ, J.; ESQUIVEL GUERRERO, J. A.; MOLINA, F. y DE LA TORRE, F. 1988: "Los ajuares cerámicos de la necrópolis argárica de la Cuesta del Negro (Purullena, Granada). Avance del estudio analítico y estadístico". Cuadernos de Prehistoria de la Universidad de Granada 12-13: 135-155.

DE LA BANDERA ROMERO, M. L. y CHAVES TRISTÁN, F. (eds.) 1994: Métodos Analíticos y su Aplicación a la Arqueología. Écija. Gráficas Sol.

ESTRADA, F.; ONTALBA SALAMANCA, M. A.; RESPALDIZA GALISTEO, M. A.; PÉREZ QUESADA, P. y HURTADO PÉREZ, V. 1999: "Técnicas nucleares 
aplicadas al estudio de cerámicas del Calcolítico extremeño". En Capel Martínez, J. (Ed.): Arqueometría y Arqueología: 77-88. Granada. Universidad de Granada.

FELIÚ ORTEGA, M. J. 1993: Aplicación de la Microscopía Electrónica de Barrido a la Arqueometría. Tesis doctoral inédita. Cádiz. Universidad de Cádiz.

FELIÚ ORTEGA, M. J.; MARTÍN CALLEJA, J.; EDREIRA SÁNCHEZ, M. C.; FERNÁNDEZ LORENZO, M. C.; MARTÍNEZ BRELL, M. P.; GIL MONTEO, A. y ALCÁNTARA PUERTO, R. (eds.) 2004: Avances en Arqueometría 2003. Cádiz. Universidad de Cádiz.

FERNÁNDEZ CACHO, S. y GARCÍA SANJUÁN, L. 1995: "Clásica Arqueología, Antigua Historia. Ensayo en torno a un desencuentro en la tradición historiográfica de Andalucía Occidental". Spal. Revista de Prehistoria y Arqueología 2: 57-79.

FERNÁNDEZ NAVARRO, E. 2002: Tradición Tecnológica y Evolución de la Cerámica de Cocina desde Comienzos de Época Almohade Hasta Finales de la Época Nazarí. Tesis doctoral inédita. Granada. Universidad de Granada.

GALVÁN MARTÍNEZ, V. 1991: Análisis Mineralógico y Geoquímico de Cerámicas procedentes del Sureste Peninsular. Tesis doctoral inédita. Madrid. Universidad Autónoma de Madrid.

GARCÍA HERAS, M. 1995: "En torno a la arqueometría española en 1995". Complutum 6: 279-280.

- 1997: "Estudio bibliométrico de los trabajos de caracterización sobre materiales cerámicos arqueológicos en España: una valoración”. Revista d'Arqueología de Ponent 7: 129-150.

- 2003: "Malos tiempos para la lírica ¿Hay todavía futuro para la arqueología científica en la universidad española?". Complutum 14: 7-18.

GARCÍA HERAS, M y OLEATXEA, C. 1992: "Métodos y análisis para la caracterización de cerámicas arqueológicas. Estado actual de la investigación en España". Archivo Español de Arqueología 65: 263-289.

GÓMEZ MORÓN, A. y POLVORINOS DEL RÍO, A. 1997: "Informe de caracterización mineralógica, química y óptica de piezas arqueológicas del yacimiento de la Casa del Marqués del Saltillo (Carmona, Sevilla)". En M. Belén Deamos, R. Anglada Curado; J.L. Escacena Carrasco; A. Jiménez Hernández; R. Lineros; I. Rodríguez (eds.): Arqueología en Carmona (Sevilla). Excavaciones en la Casa Palacio del Marqués de Saltillo. 313-334. Sevilla. Junta de Andalucía.

GÓMEZ MORÓN, M. A.; FERNÁNDEZ CACHO, S. y POLVORINOS DEL RÍO, A. J. 1995: "Roman ceramics production and archaeometry in Algeciras (Cadiz, Spain)". En I. Fabbri (ed.): Fourth Euro-Ceramics. Volume 14. The Cultural Ceramic Heritage. 3rd European Meeting on Ancient Ceramics. Archaeometric and Archaeological Studies: 257-267. Faenza.

GÓMEZ MORÓN, A.; POLVORINOS DEL RÍO, A.;
ONTALBA, A.; RESPALDIZA, A.; HURTADO PÉREZ, V.; KISS, A. Z. y BORBELINE-KISS, I. 1999: "Estudio arqueométrico de cerámicas calcolíticas del yacimiento de La Pijotilla (Badajoz, Spain)". Actes del IV Congrés Europeu sobre Ceramica Antigua (4th European Meeting on Ancient Ceramics, Andorra, November 1997): 159-167. Andorra. Govern d'Andorra.

GÓMEZ TUBÍO, B.; RESPALDIZA GALISTEO, M. A. y PARDO RODRÍGUEZ, M. L. (eds.) 2001: Actas del III Congreso Nacional de Arqueometría. (Sevilla, Septiembre de 1999). Sevilla. Universidad de Sevilla.

GONZÁLEZ VÍLCHEZ, M. C. 1982: Estudio Físico-Químico y Tecnológico de una Serie de Productos Cerámicos del Yacimiento Arqueológico de Valencina de la Concepción (Sevilla). Tesis doctoral inédita. Sevilla. Universidad de Sevilla.

- 1994: "Aplicación de métodos físico-químicos al estudio de pastas cerámicas en arqueología". En M. de la Bandera Romero y F. Chaves Tristán (eds.): Métodos Analíticos y su aplicación a la Arqueología, 119-130. Écija.

GONZÁLEZ VÍLCHES, M. C.; GONZÁLEZ GARCÍA, F.; GARCÍA RAMOS, G. y GONZÁLEZ RODRÍGUEZ, M. 1988: "Estudio arqueométrico de pigmentos de algunas piezas cerámicas de Cerro Macareno (Sevilla)." Boletín de la Sociedad Española de Cerámica y Vidrio 27(2): 73-80.

HENDERSON, J. 2000: The Science and Archaeology of Materials. An Investigation of Inorganic Materials. London. Routledge.

JAKES, K.A. (ed.) 2004: Archaeological Chemistry. Materials, Methods and Meaning. Washington DC. American Chemical Society.

KILIKOGLOU, V.; HEIN, A. y MANIATIS, Y. (eds.) 2002: Modern Trends in Scientific Studies of Ancient Ceramics. Papers Presented at the Fifth European Meeting on Ancient Ceramics (Athens, 1999). British Archaeological Reports. International Series 1011. Oxford. Archaeopress.

LINDAHL, A. y STILBORG, O. 1995: The Aim of Laboratory Analysis of Ceramics in Archaeology. Stockholm. Kungl.

MARTÍN DE LA CRUZ, J. C. 1990: "Die erste mykenische keramik von der Iberischen Halbinsel”. Prähistorische Zeitschrift 65: 49-52. Berlín.

MIDDLETON, A. y FREESTONE, I. (eds.) 1991: Recent Developments in Ceramic Petrology. British Museum Occasional Papers 81. London. British Museum.

MOMMSEN, H.; DIEHL, U.; LAMBRECHT, D.; PANTENBURG, F. J. y WEBER, J. 1990: "Eine mykenische scherbe in Spanien: bestätigung ihrer herkunft mit der neutronenactivierungsanalyse (NAA)". Prähistorische Zeitschrift 65: 59-61. Berlín.

MOSQUERA DÍAZ, M. J.; RUIZ HERRERA, E. y FELIÚ ORTEGA, M. J. 2001: “Aplicación de la técnica de 
porosimetría de intrusión de mercurio (MIP) a la caracterización de cerámicas de origen tarteso". En B. Gómez Tubío; M.A. Respaldiza Galisteo y M.L. Pardo Rodríguez (eds.): Actas del III Congreso Nacional de Arqueometría. (Sevilla, Septiembre de 1999): 335-339. Sevilla. Universidad de Sevilla.

NAVARRETE ENCISO, M. S.; CAPEL MARTÍNEZ, J.; LINARES, J.; HUERTAS, F. y REYES, E. 1991: $\mathrm{Ce}$ rámicas Neolíticas de la Provincia de Granada. Materias Primas y Técnicas de Manufacturación. Granada. Universidad de Granada.

ONTALBA SALAMANCA, M. A. 2000: Estudios Arqueométricos Mediante Técnicas Nucleares. Tesis doctoral inédita. Sevilla. Universidad de Sevilla.

ORNA, M. V. (ed.) 1996: Archaeological Chemistry. Organic, Inorganic, and Biochemical Analysis. Washington. American Chemical Society.

PELÁEZ COLILLA, M. N. 1983: "Puesta a punto de algunas técnicas físico-químicas para el estudios de cerámicas arqueológicas". Cuadernos de Prehistoria y Arqueología de la Universidad Autónoma de Madrid 9-10: 151-210.

PÉREZ ARANTEGUI, J.; AGUAROD OTAL, C.; LAPUENTE MERCADAL, M. P.; FELIÚ ORTEGA, M. J. y PERNOT, M. 1996: Arqueometría y Caracterización de Materiales Cerámicos. Cuadernos del Instituto Aragonés de Arqueología 4. Teruel. Universidad de Teruel.

PÉREZ ARANTEGUI, J.; LAPUENTE MERCADAL, M. P.; AGUAROD OTAL, M. C. y CASTILLO SUÁREZ, J. R. (eds.) 1999: Actas del II Congreso Nacional de Arqueometría (Zaragoza, 1997). Caesaraugusta 73. Zaragoza. Institución Fernando El Católico, CSIC.

POLLARD, M. y HERON, C. 1996: Archaeological Chemistry. Cambridge. The Royal Society of Chemistry.

POLVORINOS DEL RÍO, A. 1998: "Análisis arqueométrico de las cerámicas de la necrópolis de La Traviesa". En L. García Sanjuán (ed.): La Traviesa. Ritual Funerario y Jerarquización Social en una Comunidad de la Edad del Bronce de Sierra Morena Occidental. Spal Monografías 1: 271-293. Sevilla. Universidad de Sevilla.

- 1999: "Caracterización de cerámicas y materiales constructivos de los hornos de Plaza de Lasso (Carmona, Sevilla)". Caesaraugusta 73: 131-139.

- 2001a: "Contribución de la granulometría del desgrasante a la clasificación de texturas cerámicas arqueológicas”. En B. Gómez Tubío; M.A. Respaldiza Galisteo y M.L. Pardo Rodríguez (eds.): Actas del III Congreso Nacional de Arqueometría (Sevilla, Septiembre de 1999): 349-357. Sevilla. Universidad de Sevilla.

- 2001b: "Análisis espacial de la textura de cerámicas arqueológicas por métodos geoestadísticos”. En B. Gómez Tubío; M.A. Respaldiza Galisteo y M.L. Pardo Rodríguez (eds.): Actas del III Congreso Nacional de
Arqueometría (Sevilla, Septiembre de 1999): 341-348. Sevilla. Universidad de Sevilla.

POLVORINOS DEL RÍO, A.; GÓMEZ MORÓN, A. y HURTADO PÉREZ, V. 1999: “Análisis morfométrico de cerámicas calcolíticas del yacimiento de La Pijotilla (Badajoz, España)". Actes del 4t Congrés Europeu sobre Ceramica Antigua (4th European Meeting on Ancient Ceramics, Andorra, November 1997): 250261. Andorra. Govern d'Andorra.

POLVORINOS DEL RÍO, A.; HURTADO PÉREZ, V. y GÓMEZ MORÓN, M.A. 2001: "Análisis arqueométrico del yacimiento de El Trastejón”. En B. Gómez Tubío; M.A. Respaldiza Galisteo y M.L. Pardo Rodríguez (eds.): Actas del III Congreso Nacional de Arqueometría. (Sevilla, Septiembre de 1999): 215-225. Sevilla. Universidad de Sevilla.

POLVORINOS DEL RÍO, A.; GARCÍA SANJUÁN, L.; HURTADO PÉREZ, V. y HERNÁNDEZ ARNEDO, M. J. 2005: "Bronze Age ceramics in South-west Spain: an exploratory archaeometric study of technology and function". Geoarchaeology 20 (3): 263-284.

RAMOS MUÑOZ, J.; DOMÍNGUEZ-BELLA, S. y MORATA-CÉSPEDES, D. 1997: “Alternativas no adaptativas para la integración de técnicas mineralógicas y petrológicas dentro de una arqueología como proyecto social". Revista Atlántica-Mediterránea de Prehistoria y Arqueología Social 1: 223-229.

RINCÓN, J. M. 1981: "Estudio comparativo de los colorantes superficiales rojos de varias piezas cerámicas del poblado de La Muela de Cástulo (Linares, Jaén)”. En J.M. Blázquez y J. Valiente (eds.): Cástulo III. EAE 117: 243-249. Madrid. Ministerio de Cultura.

ROLDAN, C. (ed.) 2002: Actas del IV Congreso Nacional de Arqueometría (Valencia 15-17 de Octubre de 2001). Valencia. Universidad de Valencia.

SINOPOLI, C. M. 1991: Approaches to Archaeological Ceramics. New York. Plenum Press.

TITE, M. 1999: "Pottery production, distribution and consumption. The contribution of the physical sciences". Journal of Archaeological Method and Theory 6 (3): 181-235. New York. Plenum Publishing.

VENDRELL-SAZ, M.; PRADELL, T. ; MOLERA, J. y GARCIA, M. (eds.) 1995: Studies on Ancient Ceramics. Proceedings of the European Meeting on Ancient Ceramics (Barcelona, 1993). Barcelona. Generalitat de Catalunya.

VILA I MITJÀ, A. (ed.) 1991: Arqueología. Madrid. CSIC. VILA I MITJÀ, A. y ESTEVEZ ESCALERA, J. 1989: "Sola ante el peligro: la Arqueología ante las ciencias auxiliares". Archivo Español de Arqueología 62: 272276.

WHITBREAD, I. K. 2001: "Ceramic petrology, clay geochemistry and ceramic production. From technology to the mind of the potter". En D.R. Brothwell y A.M. Pollard (eds.): Handbook of Archaeological Sciences: 449-459. Chichester. John Wiley and Sons. 


\section{Apéndice 1.}

\section{YACIMIENTOS Y MUESTRAS INCLUIDAS EN EL ESTUDIO}

\begin{tabular}{|c|c|c|c|c|}
\hline YACIMIENTO & PROVINCIA & PERIODO & $\begin{array}{c}\mathbf{N}^{\mathbf{0}} \\
\text { MUES- } \\
\text { TRAS }\end{array}$ & REFERENCIA \\
\hline Almizaraque & Almería & $\begin{array}{l}\text { Neolítico y } \\
\text { Edad del Cobre }\end{array}$ & 49 & Galván Martínez et al. 1993 \\
\hline Arva & Sevilla & Romano & 15 & Guiraum et al. 1995 \\
\hline Astigi & Sevilla & Romano & 19 & Guiraum et al. 1995 \\
\hline Cabezo de San Pedro & Huelva & $\begin{array}{l}\text { Edad del Bron- } \\
\text { ce }\end{array}$ & 8 & Barrios Neira et al. 1994; Galván 1986. \\
\hline Calañas de Marmolejo & Jaén & Edad del Hierro & 23 & Molinos Molinos et al. 1994 \\
\hline Campos & Almería & $\begin{array}{l}\text { Neolítico y } \\
\text { Edad del Cobre }\end{array}$ & 22 & Galván, 1991; Martín Socas et al. 1986 \\
\hline $\begin{array}{l}\text { Casa del Marqués de Salti- } \\
\text { llo }\end{array}$ & Sevilla & Edad del Hierro & 21 & $\begin{array}{l}\text { Gómez Morón et al. 1997; Navarro Gascón. } \\
1997\end{array}$ \\
\hline Cástulo & Jaén & $\begin{array}{l}\text { Edad del Bron- } \\
\text { ce, Edad del } \\
\text { Hierro y Ro- } \\
\text { mano } \\
\end{array}$ & 27 & Rincón. 1985 \\
\hline Cerro de la Cabeza & Sevilla & Edad del Hierro & 5 & Galván 1986 \\
\hline Cerro de la Corona & Málaga & Neolítico & 2 & Domínguez et al. 1998 \\
\hline Cerro de San Pedro & Huelva & $\begin{array}{l}\text { Edad del Bron- } \\
\text { ce }\end{array}$ & 4 & Rincón 1985 \\
\hline Cerro del Villar & Málaga & Edad del Hierro & 16 & Cardell et al. 1999 \\
\hline Cerro Macareno & Sevilla & $\begin{array}{l}\text { Bronce y Edad } \\
\text { del Hierro }\end{array}$ & 73 & González Vílches et al. 1984; 1985 \\
\hline Córdoba & Córdoba & Romano & 22 & Bernal Casasola et al. 1995 \\
\hline Cortijo de Baladrar & Almería & Edad del Cobre & 2 & Galván 1991 \\
\hline $\begin{array}{l}\text { Cortijo del Molino de la } \\
\text { Higuera }\end{array}$ & Almería & Edad del Cobre & 1 & Galván 1991 \\
\hline Cuartillas & Almería & Neolítico & 119 & Galván 1991 \\
\hline Cueva de la Carigüela & Granada & Neolítico & 71 & $\begin{array}{l}\text { Capel Martínez et al. 1983; Navarrete et al. } \\
1991\end{array}$ \\
\hline Cueva de la Mujer & Granada & Neolítico & 6 & Navarrete et al. 1991 \\
\hline Cueva de la Ventana & Granada & Neolítico & 5 & Navarrete et al. 1991 \\
\hline Cueva de las Campanas & Granada & \begin{tabular}{|l|} 
Neolítico \\
\end{tabular} & 5 & Navarrete et al. 1991 \\
\hline Cueva de los Molinos & Granada & Neolítico & 5 & Navarrete et al. 1991 \\
\hline Cueva de Malalmuerzo & Granada & Neolítico & 7 & Navarrete et al. 1991 \\
\hline $\begin{array}{l}\text { Cueva del Agua de Prado } \\
\text { Negro }\end{array}$ & Granada & Neolítico & 12 & Navarrete et al. 1991 \\
\hline Cueva del Agua & Granada & \begin{tabular}{|l|} 
Neolítico \\
\end{tabular} & 8 & Navarrete et al. 1991 \\
\hline Cueva del Capitán & Granada & Neolítico & 4 & Navarrete et al. 1991 \\
\hline Cueva del Conejo & Granada & Neolítico & 6 & Navarrete et al. 1991 \\
\hline Cueva del Coquino & Granada & \begin{tabular}{|l|} 
Neolítico \\
\end{tabular} & 14 & Navarrete et al. 1991 \\
\hline Dolmen de Alberite & Cádiz & Neolítico & 5 & Feliú et al. 1996 \\
\hline El Llanete de los Moros & Córdoba & $\begin{array}{l}\text { Bronce y Edad } \\
\text { del Hierro }\end{array}$ & 14 & Galván García et al. 1987 \\
\hline El Retamar & Cádiz & Neolítico & 8 & Lazarich González et al. 2002 \\
\hline El Rinconcillo & Cádiz & Romano & 40 & $\begin{array}{l}\text { Gómez Morón et al. 1995; Gómez Morón et } \\
\text { al. } 2001\end{array}$ \\
\hline
\end{tabular}




\begin{tabular}{|c|c|c|c|c|}
\hline El Trastejón & Huelva & $\begin{array}{l}\text { Edad del Bron- } \\
\text { ce }\end{array}$ & 12 & Polvorinos et al. 2001 \\
\hline Hacho de Benameji & Córdoba & Edad del Hierro & 2 & Barrios Neira et al. 1994 \\
\hline $\begin{array}{l}\text { Hospital de las Cinco Lla- } \\
\text { gas }\end{array}$ & Sevilla & Romano & 21 & Polvorinos et al. 2001 \\
\hline Huelva & Huelva & Edad del Hierro & 29 & Arribas et al. 1989 \\
\hline La Losa & Almería & Edad del Cobre & 1 & Galván 1991 \\
\hline La Molaina & Granada & \begin{tabular}{|l|} 
Neolítico \\
\end{tabular} & 6 & Navarrete et al. 1991 \\
\hline La Muela de Santaella & Córdoba & $\begin{array}{l}\text { Bronce y Edad } \\
\text { del Hierro }\end{array}$ & 5 & Barrios Neira et al. 1994 \\
\hline La Traviesa & Sevilla & $\begin{array}{l}\text { Edad del Bron- } \\
\text { ce }\end{array}$ & 11 & Polvorinos 1998 \\
\hline Laderas de Morana & Córdoba & Edad del Hierro & 1 & Barrios Neira et al. 1994 \\
\hline Las Majolicas & Granada & Neolítico & 6 & Navarrete et al. 1991 \\
\hline Las Pilas de Mojácar & Almería & Edad del Cobre & 1 & Galván 1991 \\
\hline Loma de Ceres & Granada & Romano & 26 & $\begin{array}{l}\text { Nogueras Vega et al. 1997; Rodríguez Gordi- } \\
\text { llo et al. } 1988\end{array}$ \\
\hline Los Silos de Vera & Almería & Neolítico & 2 & Galván, 1991 \\
\hline Los Villares de Yújar & Jaén & Romano & 21 & García Jiménez et al. 1999 \\
\hline Madinat Al-Zahra & Córdoba & Medieval & 16 & González García et al. 1992 \\
\hline Monturque & Córdoba & $\begin{array}{l}\text { Edad del Co- } \\
\text { bre, Bronce y } \\
\text { Edad del Hierro }\end{array}$ & 17 & $\begin{array}{l}\text { Barrios et al. 1991; Barrios Neira et al. } \\
1994\end{array}$ \\
\hline Plaza de Lasso & Sevilla & Romano & 17 & Polvorinos 1997 \\
\hline Poblado de los Castillejos & Granada & Neolítico & 12 & Navarrete et al. 1991 \\
\hline Salobreña & Granada & Romano & 12 & de Andrés et al. 1993 \\
\hline San Bartolomé de Almonte & Huelva & $\begin{array}{l}\text { Bronce y Edad } \\
\text { del Hierro }\end{array}$ & 27 & Galván 1986 \\
\hline Sevilla & Sevilla & Contemporáneo & 30 & Flores Alés et al. 1999 \\
\hline Sima de los Intentos & Granada & Neolítico & 3 & Capel et al. 1986 \\
\hline Sima Rica & Granada & Neolítico & 5 & Navarrete et al. 1991 \\
\hline Tejada la Vieja & Huelva & Edad del Hierro & 10 & Arribas et al. 1989 \\
\hline Torre de Doña Blanca & Cádiz & Edad del Hierro & 8 & Galván 1986 \\
\hline Valencina de la Concepción & Sevilla & Edad del Hierro & 2 & Galván 1986 \\
\hline Venta del Carmen & Cádiz & Romano & 26 & Vigil et al. 1998 \\
\hline Zajara & Almería & Edad del Cobre & 5 & Galván 1991 \\
\hline
\end{tabular}




\section{Apéndice 2.}

\section{REFERENCIAS BIBLIOGRÁFICAS INCLUIDAS EN EL ESTUDIO}

Aguayo, P.; Barahona, E.; Garrido, O. y Padial, B. 1997: "Estudio preliminar de los depósitos de arcilla utilizados para la elaboración de cerámicas arqueológicas en la Depresión Natural de Ronda". En Bernabeu, J.; Orozco, T. y Terradas, X. (eds.): Los Recursos Abióticos de la Prehistoria. Caracterización, aprovisionamiento e intercambio. Universitat de Valencia: Valencia, 173-187.

- Arribas, J.G.; Calderón, T. y Rufete, P. 1989: “Estudio mineralógico comparativo de restos arqueológicos indígenas e importados de Tejada la Vieja (Escacena) y Huelva". En Fernández Jurado, J. (ed.), Tejada la Vieja. Una Ciudad Protohistórica. Huelva Arqueológica IX: 244-257.

Barrios Neira, J.; Fernández, J.; Moreno, J. y Montealegre, L. 1999: "Cerámicas del Calcolítico y su entorno (Llano de la Virgen, Málaga, España)". Caesaraugusta 73: 8998.

- Barrios Neira, J.; Navas, J. J.; López Palomo, L. A. y Montealegre, L. 1991: "Características estructurales y mineralógicas de cerámicas campaniformes procedentes de Monturque (Córdoba)". Boletín de la Sociedad Española de Cerámica y Vidrio 30 (3): 187-193.

Barrios Neira, J.; Carmona, R. y Montealegre, L. 2001: "Cueva de los Mármoles (Córdoba). Estudio arqueométrico preliminar sobre cerámicas de la época medieval andalusí’. En Gómez Tubio, B.; Respaldizo, M. A. y Pardo Rodríguez, M. L. (eds.), Actas del III Congreso Nacional de Arqueometría (Sevilla, Septiembre de 1999). Universidad de Sevilla: Sevilla, 287-292.

- Barrios Neira, J.; López Palomo, J.L. y Montealegre Contreras, L. 1994: "Caracterización mineralógica y petroestructural de cerámicas protohistóricas". Boletín de la Sociedad Española de Cerámica y Vidrio 33 (1): 33-40.

- Bernal Casasola, D. y García Jiménez, R. 1995: "Talleres de lucernas en Colonia Patricia Corduba en Época Bajoimperial: evidencias arqueológicas y primeros resultados de la caracterización geoquímica de las pastas". Anales de Arqueología Cordobesa 6: $175-216$.

Calderón Martínez, T.; Sibilia, E. y Fernández Jurado, J. 1989: "Datación absoluta por termoluminiscencia de materiales arqueológicos procedentes de Tejada la Vieja (Escacena del Campo) y Cabezo de San Pedro (Huelva)". En Fernández Jurado, J. (ed.), Tejada la Vieja. Una ciudad protohistórica. Huelva Arqueológica IX. Diputación de Huelva: Huelva, 265-281.

- Capel Martínez, J.; Linares, J.; Huertas, F y Muñoz, J. P. 1986: "La Sima de los Intentos: estudio óptico y mineralógico". Cuadernos de Prehistoria de la Universidad de Granada 11: 65-71.

Capel Martínez, J.; Linares, J.; Huertas, F. y Navarrete Enciso, M. S. 1984: "Cerámicas con decoración a la almagra: identificación y caracterización de los términos almagra, aguada y engobe. Proceso de decoración". Cuadernos de Prehistoria de la Universidad de Granada 9: 97-114.

Capel Martínez, J.; Molina, F.; Guardiola, J. L.; Caballero, E. y Jiménez de Cisneros, C. 1999: "Identificación de la procedencia de materiales cerámicos mediante la técnica de Espectrometría de Masas de Isótopos Ligeros Estables y estudio petrológico en lámina delgada" en Capel Martínez, J. (ed.): Arqueometría y Arqueología. Monográfica Arte y Arqueología. Universidad de Granada: Granada, 89-105.

Capel Martínez, J.; Molina, F.; Nájera, T.; Linares, J. y Huertas, F. 2001: “Aproximación al estudio de procedencia y tecnología de fabricación de las cerámicas campaniformes del yacimiento de la Edad del Cobre de Los Millares". En Gómez Tubío, B.; Respaldiza Galisteo, M. A. y Pardo Rodríguez, M. L. (eds.), Actas del III Congreso Nacional de Arqueometría. (Sevilla, Septiembre de 1999). Universidad de Sevilla: Sevilla, 207214.

Capel Martínez, J.; Linares González, J. y Huertas García, F. 1979: "Métodos analíticos aplicados a cerámicas de la Edad del Bronce". Cuadernos de Prehistoria de la Universidad de Granada 4: 345-360.

- Capel Martínez, J.; Navarrete Enciso, M. S. y Reyes Camacho, E. 1983: "Aplicación de métodos analíticos al estudio de cerámicas a la almagra”. XVI Congreso Nacional de Arqueología (Murcia, 1982). Universidad de Zaragoza: Zaragoza, 95-104.

- Cardell, C.; Rodríguez Gordillo, J.; Morotti, M. y Párraga, M. 1999: “Arqueometría de cerámicas fenicias del Cerro del Villar (Guadalhorce, Málaga): 
composición y procedencia”. En Capel Martínez, J. (ed.) Arqueometría y Arqueología. Monográfica Arte y Arqueología. Universidad de Granada: Granada, 107-120.

Contreras Cortés, F.; Capel, J.; Esquivel, J.A.; Molina, F. y de la Torre, F. 1988: "Los ajuares cerámicos de la necrópolis argárica de la Cuesta del Negro (Purullena, Granada). Avance del estudio analítico y estadístico". Cuadernos de Prehistoria de la Universidad de Granada 12-13: 135-155.

- de Andrés, A.; Muñoz, I.; García Ramos, G. y Vargas, M. 1993: "Caracterización de cerámicas romanas de Salobreña (Granada) II: Época imperial (s. IIIII d.C.)". Boletín de la Sociedad Española de Cerámica y Vidrio 32 (1): 45-47.

- Domínguez, S. y Morata, D. 1998: "Estudio analítico de los materiales del dolmen del Cerro de la Corona. Técnicas Experimentales y su Aplicación a los estudios arqueológicos". En Recio Ruiz, A. et alii (eds.): El Dolmen del Cerro de la Corona de Totalán. Contribución al Estudio de la Formación Económico-Social Tribal en la Axarquía de Málaga. Diputación Provincial de Málaga: Málaga, 53-61.

Feliú, M. J.; Martín, J. y Edreira, M. C. 1996: "Estudio analítico de materiales arqueológicos: cuentas, cerámicas y ocres". En Ramos Muñoz, J. y Giles Pacheco, F. (eds.): El Dolmen de Alberite. Aportaciones a las Formas Económicas y Sociales de las Comunidades Neolíticas en el Noroeste de Cádiz. Universidad de Cádiz: Cádiz, 207-237.

Fernández Navarro, E. 2002: Tradición Tecnológica y Evolución de la Cerámica de Cocina desde Comienzos de Época Almohade Hasta Finales de la Época Nazarí. Tesis doctoral inédita. Granada. Universidad de Granada

Flores Alés, V.; Guiraúm Pérez, A. y Barrios Sevilla, J. 1999: "Estudio de una selección de ladrillos y tégulas del yacimiento de Urso (Sevilla)". Caesaraugusta 73: 125-129.

- Flores Alés, V.; Guiraúm Pérez, A. y Barrios Sevi1la, J. 1999: "Caracterización de ladrillería tradicional producida en la Vega del Guadalquivir en zonas próximas a Sevilla". Boletín de la Sociedad Española de Cerámica y Vidrio 38 (1): 29-34.

- Galván Martínez, V. 1986: "Análisis de pastas cerámicas”. Huelva Arqueológica 8: 275-331.

- Galván Martínez, V. 1991. Análisis Mineralógico y
Geoquímico de Cerámicas Procedentes del Sureste Peninsular. Tesis doctoral inédita. Madrid Universidad Autónoma de Madrid

- Galván García, J. R. y Galván Martínez, V. 1987: "Estudio mineralógico de cerámicas procedentes de El Llanete de Los Moros (Montoro, Córdoba)". En Martín de la Cruz, J.C. (ed.), El Llanete de los Moros (Montoro, Córdoba). E.A.E. 150. Ministerio de Cultura: Madrid, 270-278.

- Galván Martínez, V. y Galván García, J. 1993. "Las almagras de Almizaraque: composición mineralógica, tecnología y proceso de cocción". Cuadernos de Prehistoria y Arqueología de la Universidad Autónoma de Madrid 20: 9-25.

- García Giménez, R.; Bernal Casasola, D. y Morillo Cerdán, A. 1999. "Consideraciones sobre los centros productores de lucernas tipo Yújar: Análisis arqueométrico de materiales procedentes de Los Villares de Yújar (Jaén) y de la submeseta norte". En Capel Martínez, J. (ed.): Arqueometría y Arqueología. Monográfica Arte y Arqueología. Universidad de Granada: Granada, 187-195.

García Ramos, G. 1990. "Estudio de los materiales cerámicos arqueológicos de Salobreña y su entorno y su relación con las arcillas de la región". $V$ Centenario de la Incorporación de Salobreña a la Corona de Castilla (1489-1989). Caja de Ahorros La General: Salobreña, 29-53.

- Gómez Morón, M. A.; Fernández Cacho, S. y Polvorinos del Río, A. J. 1995. "Roman ceramics production and archaeometry in Algeciras (Cadiz, Spain)". En Fabbri, I. (Ed.): Fourth Euro-Ceramics. Volume 14. The Cultural Ceramic Heritage. 3rd European Meeting on Ancient Ceramics. Archaeometric and Archaeological Studies. Faenza: 257267.

- Gómez Morón, M. A. y Polvorinos del Río, A. J. 1997: "Informe de caracterización mineralógica, química y óptica de piezas cerámicas arqueológicas del yacimiento de la Casa del Marqués de Saltillo (Carmona, Sevilla)". En Belén Deamos, M.; Anglada Curado, R.; Escacena Carrasco, J. L.; Jiménez Hernández, A.; Lineros, R.; Rodríguez I.: Arqueología en Carmona. Excavaciones en la Casa-Palacio del Marqués de Saltillo. Junta de Andalucía: Sevilla.

- Gómez Morón, M. A.; Polvorinos del Río, A. y Fernández Cacho, S. 2001: "Caracterización arqueométrica de las producciones del Alfar de El 
Rinconcillo (Cádiz, España)” En Gómez Tubío, B.; Respaldiza Galisteo, M. A. y Pardo Rodríguez, M. L. (eds.): Actas del III Congreso Nacional de Arqueometría. (Sevilla, Septiembre de 1999). Universidad de Sevilla: Sevilla, 239-250.

- González García, F.; González Rodríguez, M.; González Vilches, M. C. y Vallejo Triano, A. 1992: "Estudio arqueométrico de algunas cerámicas medievales de Madinat Al-Zahra (Córdoba)". Boletín de la Sociedad Española de Cerámica y Vidrio 31 (6): 491-498.

González Vilches, M. C. 1982: Estudio Físico-Químico y Tecnológico de una Serie de Productos Cerámicos del Yacimiento Arqueológico de Valencina de la Concepción (Sevilla). Tesis doctoral inédita. Sevilla. Universidad de Sevilla

- González Vilches, M. C.; García Ramos, G. y González García, F. 1984: "Materias primas y datos tecnológicos de piezas cerámicas antiguas del yacimiento arqueológico de Cerro Macareno (Sevilla) I". Boletín de la Sociedad Española de Cerámica y Vidrio 24 (3): 173-186.

- González Vilches, M. C.; García Ramos, G. y González García, F. 1985: "Materias primas y datos tecnológicos de piezas cerámicas antiguas del yacimiento arqueológico de Cerro Macareno (Sevilla) II". Boletín de la Sociedad Española de Cerámica y Vidrio 25 (4): 219-233.

González Vilches, M. C. y Ruiz Abrio, T. 1986: “Análisis de pastas y pinturas en cerámicas 'orientalizantes' andaluzas”. Madriler Mitteilungen 27: 146-150.

- Guiraum, A.; Barrios, J. y Flores Alés, V. 1995: “A group of Roman ceramic building materials from the settlements of Astigi y Arva in the province of Seville (Spain)". En Fabbri, I. (Ed.): Fourth EuroCeramics. Volume 14. The Cultural Ceramic Heritage. 3rd European Meeting on Ancient Ceramics. Archaeometric and Archaeological Studies. Faenza: 363-370.

- Lazarich González, M.; Feliú Ortega, M. J.; Edreira Sánchez, C. y Calleja Gonzalo, S. 2002: "Los productos cerámicos de El Retamar. Análisis tecnológico, morfológico y funcional". En Ramos Muñoz, J. y Lazarich González, M. (eds.): Memoria de la Excavación Arqueológica en el Asentamiento del VI milenio A.N.E. de El Retamar (Puerto Real, Cádiz). Junta de Andalucía: Sevilla, 157-164.

Leguey, S.; Carretero, M.I.; Fabbri, B. y Galán, E. 2001:
“Caracterización mineralógica y química de los ladrillos de la Torre del Oro de Sevilla: una aproximación a la temperatura de cocción y origen de las materias primas”. Boletín de la Sociedad Española de Cerámica y Vidrio 40 (6): 455-459.

Martín de la Cruz, J.C. y Perlines Benito, M. 1993: "La cerámica a torno de los contextos culturales de finales del III milenio A.C. en Andalucía”. Actas del Ier Congreso de Arqueología Peninsular (Porto, 12-18 de Octubre de 1993). Sociedade Portuguesa de Antropología e Etnología: Porto. Vol. II: 335-345.

- Martín Socas, D.; Camalich Massieu, M. D.; Tejedor Salguero, M. L.; Rodríguez Rodríguez, A. y González Quintero, P. 1985: “Composición mineralógica y evaluación de las temperaturas de cocción de la cerámica de Campos (Cuevas del Almanzora, Almería). Estudio preliminar". Cuadernos de Prehistoria de la Universidad de Granada 10: 131185.

Martínez Fernández, M. J. y Gavilán Ceballos, B. 1997: "Análisis de explotación del territorio a través de la captación de arcilla por parte de una sociedad neolítica". II Congreso de Arqueología Peninsular. Tomo II: Neolítico, Calcolítico y Bronce. Fundación Rei Afonso Henriques: Zamora, 77-82.

Martínez Fernández, M. J.; Gavilán Cevallos, B.; Barrios Neira, J. y Montealegre Contreras, L. 1999: "Materias primas colorantes en Murciélagos de Zuheros (Córdoba): caracterización y procedencia”. II Congrés del Neolític a la Peninsula Ibèrica. Saguntum-PLAV Extra 2: 111-116.

Millán, A.; Arribas, J.G.; Beneitez, P.; Calderón, T. y Rufete, P. 1990: "Caracterización mineralógica de cerámicas de filiación fenicia, griega y turdetana de Huelva". Huelva Arqueológica XII: 401-446.

- Molinos Molinos, M.; Rísquez Cuenca, C.; Serrano Peña, J. L. y Montilla Pérez, S. 1994: Un Problema en la Periferia de Tartessos: Las Calañas de Marmolejo (Jaén). Universidad de Jaén: Jaén, 8299.

- Navarrete, M. S.; Capel, J.; Linares, J.; Huertas, F. y Reyes, E. 1991: Cerámicas Neolíticas de la Provincia de Granada. Materias primas y técnicas de manufacturación. Monográfica Arte y Arqueología. Universidad de Granada: Granada.

- Navarro Gascón, J. V. 1997: "Estudio analítico de los materiales cerámicos del yacimiento arqueológico de la Casa del Marqués de Saltillo (Carmona, 
Sevilla)". En Belén et al., Arqueología en Carmona. Excavaciones en la casa-palacio del Marqués de Saltillo. Junta de Andalucía: Sevilla.

- Nogueras Vega, S.; Durán Suárez, J.; Cardell Fernández, C.; Pérez Cruz, M.A.; Sánchez Navas, A.; Marín Díaz, N. y Rodríguez Gordillo, J. 1999: “Cerámica común romana del yacimiento de Loma de Ceres (Granada, España). Primeros datos sobre tecnología y procedencia de materiales". Caesaraugusta 73: 109-115.

Padial, B.; Garrido, O.; Barahona, E.; Aguayo, P. y Carrilero, M. 2000: "Estudios analíticos de un conjunto de ánforas de tipología fenicia occidental del asentamiento protohistórico de Ronda la Vieja (Ronda, Málaga)" Actas del IV Congreso Internacional de Estudios Fenicios y Púnicos, 1995. Universidad de Cádiz: Cádiz, 1841-1850.

- Polvorinos del Río, A. 1999: “Caracterización de cerámicas y materiales constructivos de los hornos de Plaza de Lasso (Carmona, Sevilla)". Caesaraugusta 73: 131-139.

- Polvorinos del Río, A. 1998: “Análisis arqueométrico de las cerámicas de la necrópolis de La Traviesa”. En García Sanjuán, L. (ed.): La Traviesa. Ritual funerario y Jerarquización Social en una Comunidad de la Edad del Bronce de Sierra Morena Occidental. Spal Monografías I. Universidad de Sevilla: Sevilla, 271-293.

- Polvorinos del Río, A.; Flores-Alés, V. y Tabales Rodríguez, M. A. 2001: “Arqueometría de Cerámicas romanas procedentes del Hospital de las Cinco Llagas de Sevilla”. IV Congreso Nacional de Arqueometría. Universitat de Valencia: Valencia.

- Polvorinos del Río, A.; Hurtado Pérez, V.M. y Gómez Morón, M.A. 2001: “Análisis arqueométrico del yacimiento de El Trastejón”. En Gómez Tubio, B.; Respaldizo, M. A. y Pardo Rodríguez, M. L. (eds.), Actas del III Congreso Nacional de Arqueometría. (Sevilla, Septiembre de 1999). Universidad de Sevilla: Sevilla, 215-225.

- Rincón, J. M. 1985: "Estudio mineralógico de piezas cerámicas de la Edad del Bronce del poblado de La Muela de Cástulo”. En Blázquez, J.M.; García-
Gelabert, M. P. y López Pardo, F. (eds.) Cástulo V. EAE 140. Ministerio de Cultura: Madrid, 319-328.

- Rincón, J. M. 1985: “Análisis mineralógico de piezas de cerámica común e ibérica de Cástulo”. En Blázquez, J.M.; García-Gelabert, M. P. y López Pardo, F. (eds.) Cástulo V. EAE 140. Ministerio de Cultura: Madrid, 329-340.

- Rincón, J. M. 1985: “Mineralogía de las cerámicas de la Edad de Bronce del yacimiento del Cerro de San Pedro (Huelva)" En Blázquez, J.M.; GarcíaGelabert, M. P. y López Pardo, F. (eds.) Cástulo V. EAE 140. Ministerio de Cultura: Madrid, 341-345.

- Rincón, J. M. 1985: “Composición mineralógica y microestructura de cerámicas "Terra Sigillata" de la Península Ibérica". En Blázquez, J.M.; García-Gelabert, M. P. y López Pardo, F. (eds.) Cástulo V. EAE 140. Ministerio de Cultura: Madrid, 346-396.

Rísquez Cuenca, C. y Molina Cámara, J.M. 1999: “Estudio de cerámicas arqueológicas en lámina delgada (Las Calañas de Marmolejo, Jaén)" En Capel Martínez, J. (ed.): Arqueometría y Arqueología. Monográfica Arte y Arqueología. Universidad de Granada: Granada, 121131.

- Rodríguez Gordillo, J. y Marín Díaz, N. 1988: “Estudio mineralógico de materiales cerámicos encontrados en la villa romana de Loma de Ceres. Establecimiento de sus temperaturas de cocción" Cuadernos de Prehistoria de la Universidad de Granada 12-13: 231-235.

Vendrell-Saz, M.; Pradell, T.; García-Vallés, M. y Molera, J. 1995: "Black and red sigillata coatings from the Yújar workshop (Jaen, Spain): characterization y technology of production". En Fabbri, I. (Ed.): Fourth EuroCeramics. Volume 14. The Cultural Ceramic Heritage. $3 r d$ European Meeting on Ancient Ceramics. Archaeometric and Archaeological Studies. Faenza: 239-247.

- Vigil, R.; Cuevas, J. y García, R. 1998: "Caracterización mineralógica y físico-química de las pastas de las cerámicas de producción local”. En Bernal Casasola, D. (ed.): Excavaciones Arqueológicas en el Alfar Romano de la Venta del Carmen (Los Barrios, Cádiz). Universidad Autónoma de Madrid: Madrid, 291-299. 